\title{
Uma tipologia do recrutamento partidário
}

$\begin{array}{r}\text { Paulo Peres } \\ \text { Amanda Machado } \\ \hline\end{array}$

\section{Introdução ${ }^{1}$}

Conforme a sempre citada observação de Schattschneider (1942), os governos democráticos modernos são governos partidários e, consequentemente, as democracias modernas são democracias partidárias. Isso continua válido mesmo no contextual atual, a despeito das recorrentes alegações de que as instituições representativas estariam atravessando um momento de crise de legitimação. Afinal, é inegável que as organizações partidárias continuam indispensáveis ao funcionamento desse regime político - elas ainda são as responsáveis diretas pela mobilização eleitoral, pela agregação das demandas sociais em programas e projetos, pela representação política, pela produção de legislação, pela formulação e execução das políticas públicas e, enfim, pela própria dinâmica de governo (Diamond e Gunther, 2001; Gunther, Montero e Linz, 2002; Webb, Farrel e Holliday, 2002; Katz e Mair, 1993, 1995, 2002; Mair, 1997). Contudo, para continuar desempenhando todas essas atribuições, antes de qualquer coisa, os partidos devem se mostrar capazes de se regenerar, reproduzindo-se por sucessivas gerações. Ou seja, eles devem não apenas se manter em sintonia com as demandas sociais e zelar pela agregação das preferências eleitorais, mas também recorrer às estratégias mais eficientes para se "reproduzir" e, assim, assegurar sua longevidade num ambiente político que geralmente é bastante competitivo e hostil.

Visto por esse prisma, podemos dizer que os partidos somente persistirão se forem bem-sucedidos na renovação constante de seus membros e, especialmente, de suas lideranças. Essa renovação é importante por pelo menos quatro razões. Em primeiro lugar, para garantir sua reprodução ao longo do tempo, pois de nada adianta chegar ao poder e ter acesso a recursos dos mais variados se a "herança" partidária não é transmitida de alguma maneira às sucessivas gerações. Em segundo lugar, para promover necessárias adaptações em resposta às alterações do ambiente que os circunda, de modo a garantir sua sobrevivência - se não formar novas lideranças, os

\footnotetext{
${ }^{1}$ Gostaríamos de agradecer imensamente aos/às colegas do GT Partidos Políticos, da Anpocs, pelo debate extremamente rico, pelas críticas e sugestões valiosas que tiveram a generosidade de partilhar conosco nos encontros em que foram apresentadas versões anteriores deste artigo. Em especial, nossos agradecimentos a Oswaldo Amaral, Márcia Dias, Bruno Bolognesi e Glauco Peres. Também somos muito gratos aos/às colegas pareceristas pela leitura atenta e rigorosa, pelas indicações de bibliografia, pelas críticas que melhoraram nossos argumentos conceituais e pelas revisões e acréscimos sugeridos. Sem dúvida, a versão final do artigo ficou consideravelmente melhor graças ao profissionalismo e à competência dos/das pareceristas. Por fim, agradecemos ao CNPq pelo apoio financeiro que possibilitou a pesquisa relacionada com o tema deste artigo.
} 
partidos serão menos conectados com as mudanças geracionais da sociedade, tornandose menos responsivos em relação aos valores e demandas emergentes. Em terceiro lugar, a renovação permite a formação de novos quadros para a necessária reposição de lideranças preparadas para cumprir eficazmente suas funções de direção, representação e governança. Por fim, em quarto lugar, o recrutamento partidário é uma condição necessária, embora não suficiente, ao funcionamento dos governos representativos, uma vez que os partidos são as principais organizações de provimento de elites ao sistema político. Cabe às organizações partidárias, portanto, a indispensável função de recrutar futuras lideranças políticas para que o sistema representativo continue funcionando com equilíbrio.

Com efeito, sendo algo tão crucial para os partidos e para a própria democracia, deveríamos esperar uma atenção redobrada dos especialistas a todas as etapas do recrutamento partidário, em especial a filiação e a formação de quadros. Deveríamos esperar, ainda, uma preocupação constante com a construção de modelos de análise voltados à apreensão mais sistemática desse fenômeno. No entanto, quando conferimos a literatura nacional e internacional, deparamo-nos com essas duas lacunas: por um lado, praticamente não existem modelos de análise concebidos para apreender os processos iniciais e intermediários do recrutamento partidário (cf. Bruter e Harrison, 2009); por outro, em sua maioria, os estudos se concentram apenas em sua etapa final ${ }^{2}$, principalmente na seleção de candidatos ou na carreira política de elites já recrutadas ${ }^{3}$; sem contar que são escassos os modelos de análise para a padronização de estudos comparados (cf. Siavelis e Morgenstern, 2008).

O problema dessas abordagens é que elas desconsideram que o recrutamento partidário não se restringe apenas à alocação de membros já formados e, portanto, à ocupação de cargos no sistema político e nas burocracias partidária e estatal - o recrutamento deve ser compreendido em sua inteireza processual, como algo que abrange todo o percurso interno do novo membro, desde sua entrada na legenda até sua conversão em uma liderança. Na verdade, a literatura costuma focar mais o recrutamento de um modo geral, principalmente nas carreiras legislativas e executivas, do que o recrutamento para as organizações partidárias (cf. Czudnowski, 1975; Norris,

\footnotetext{
2 Evidentemente, trata-se de uma vasta literatura e, por isso, indicamos aqui apenas alguns estudos exemplares: Prewitt (1970), Seligman (1971), Black (1972), Czudnowski (1975), Eulau e Czudnowski (1976), Loewenberg e Patterson (1979), Mezey (1979), Ranney (1965, 1981), Matthews (1985), Fowler (1993), Epstein (1980), Gallagher e Marsh (1988), Camp (1995, 2008), Norris (1996, 1997, 2006), Martz (1999), Katz (2001), Rahat e Hazan (2001), Pennings e Hazan (2001), Hazan (2002); Siavelis (2002).

3 No caso do Brasil, os estudos também seguiram o mesmo padrão. Conferir, por exemplo: Fleischer (1981); Love (1982); Love e Barickman (1991); Miceli (1991); Marenco (1997, 2002, 2005, 2013); Coradini (2001, 2007); Rodrigues (2002, 2006); Samuels (2003, 2008); Müller (2005); Marenco e Serna (2007); Power e Mochel (2008); Braga, Veiga e Miríade (2009); Perissinotto e Bolognesi (2009); Perissinotto e Miríade (2009); Neiva e Izumi (2012); Braga e Bolognesi (2013); Braga e Amaral (2013); Bolognesi (2013); Costa e Codato (2013); Costa, Costa e Nunes (2014); Codato, Costa e Massimo (2015). Num estudo recente, Bolognesi e Medeiros (2014) se voltaram para a etapa inicial do recrutamento, procurando analisar as motivações subjetivas que levaram um conjunto de deputados federais de alguns partidos e estados brasileiros a entrar na carreira política. Entretanto, o grupo analisado ainda é restrito às elites já formadas e selecionadas.
} 
UMA TIPOLOGIA DO RECRUTAMENTO PARTIDÁRIO

1997; Siavelis e Morgenstern, 2008). Evidentemente, não é necessário que os partidos recrutem novos membros e lideranças seguindo um único curso linear e sequencial, pois isso depende do seu desenho organizacional e das estratégias e táticas adotadas por suas lideranças em cada circunstância ou período. Isso quer dizer que podem coexistir modalidades diferentes de recrutamento; porém, essas diferenças somente poderão ser identificadas se o conceito de recrutamento for ampliado, de maneira a ser viável a construção de uma heurística que permita apreender tais variações, até mesmo para um entendimento mais acurado dos perfis das carreiras políticas, da seleção de candidatos, da indicação para postos de direção, e assim por diante.

No contexto atual, contudo, não há uma definição conceitual abrangente o suficiente para apreender o fenômeno com tal perspectiva; tampouco há modelos tipológicos que contemplem todas as etapas do recrutamento ${ }^{4}$. Em realidade, persiste nessa agenda de pesquisa uma indistinção conceitual que torna confusamente intercambiáveis os entendimentos sobre o que seriam recrutamento político, recrutamento partidário, recrutamento legislativo e recrutamento executivo. Entendemos que, embora articulados, esses processos são específicos e devem ser devidamente demarcados. Podemos dizer que o recrutamento político é o fenômeno mais abrangente que abarca todo tipo de recrutamento para instituições que pertencem ao sistema político, como, por exemplo, os movimentos sociais, os sindicatos, as ONGs e também os próprios partidos. Isso significa que o recrutamento partidário está subsumido ao recrutamento político, uma vez que é uma de suas formas de ocorrência. O recrutamento para o Legislativo e para o Executivo, por sua vez, somente pode ocorrer, no caso de países com monopólio partidário da representação, depois de ter havido o recrutamento partidário. Então, o recrutamento para a carreira política no Legislativo e no Executivo estão subsumidos ao recrutamento partidário e correspondem ao processo de seleção de candidatos promovido pelos partidos e chancelados pelo eleitorado. Logicamente, temos o recrutamento político, que engloba o recrutamento partidário, o qual envolve o recrutamento para o Legislativo e o Executivo.

Diante disso, nosso objetivo neste artigo é precisamente este: propor uma heurística para a análise classificatória do recrutamento partidário enquanto um processo que, potencialmente, compreende três momentos, não necessariamente sequenciais: (1) a absorção de um novo filiado; (2) sua formação política no interior da organização; e (3) sua ascensão à posição de liderança e/ou no quadro burocrático. Partindo dessa concepção, apresentamos um modelo descritivo que permite identificar as diferentes estratégias partidárias implementadas para a atração e a formação de membros, assim como a seleção de elites. Isso é importante porque, em princípio, cada estratégia, submetida a constrangimentos institucionais internos e externos, produzirá impactos

\footnotetext{
4 Excetuando-se a recente proposta metodológica de Bruter e Harrison (2009), voltada à apreensão tipológica das motivações que levam os jovens à filiação partidária, não dispomos realmente de modelos de análise aptos à aplicação a todas as etapas do recrutamento. Para uma discussão mais detalha dos problemas metodológicos e conceituais da literatura, confira Siavelis e Morgenstern (2008).
} 
distintos na própria organização e no desempenho eleitoral e governamental do partido, o que, por sua vez, de forma interativa, impactará futuros tipos de recrutamento.

Para encaminhar nossa proposta, na próxima seção, "Recrutamento e filiação nas organizações partidárias", analisamos a literatura especializada com a finalidade de discutir a relação que os pesquisadores estabeleceram entre os tipos de organização partidária e as modalidades de recrutamento e formas de filiação características. Mostramos como cada tipo partidário descrito pelas teorias canônicas aparece vinculado a procedimentos diferentes de recrutamento e filiação. Mais do que isso, defendemos que, recentemente, a variedade nos modos de filiação e o uso diversificado dos tipos de recrutamento impedem uma vinculação direta das variáveis filiação e recrutamento com tipos partidários específicos. Por isso, nosso modelo permite descartar a busca dessa associação, assim como a perspectiva normativa favorável a um tipo de partido e, por extensão, de recrutamento. Nosso modelo é essencialmente descritivo. Na seção "Especificações conceituais do modelo classificatório", apresentamos a especificação epistemológica da nossa proposta de classificação. Em "Modelo tipológico do recrutamento partidário", apresentamos nossa proposta desse modelo, abarcando seus tipos, subtipos, formas, meios, modalidades e submodalidades.

\section{Recrutamento e filiação nas organizações partidárias}

Nos últimos anos, os estudos partidários convergiram para um problema comum: o acentuado declínio das filiações. Realmente, conforme mostraram sucessivas pesquisas realizadas na Europa, é cada vez menor a quantidade de filiados aos partidos (Katz et al., 1992; Scarrow, 1996, 2000; Whiteley e Seyd, 1998; Mair e Van Biezen, 2001; Dalton, 2005; Van Biezen e Kopecky, 2007; Whiteley, 2011; Delwit, 2011; Van Haute, 2011; Krouwel, 2012; Van Biezen, Mair e Poguntke, 2012). Mais do que isso, dados recentes apontam que as organizações partidárias não apenas se mostram incapazes de atrair novos membros, como também estão se esforçando arduamente, muitas vezes sem resultados, para manter os filiados que já possuem (Scarrow, 2015). Ademais, o número de membros é ainda mais reduzido nas recentes democracias da região (Kopecky, 1995; Morlino, 1998; Lewis, 2000; Van Biezen, 2003). Tal evolução levou diversos especialistas a considerar que essa variável perdeu sua validade como indicadora da capacidade organizacional dos partidos (cf. Van Biezen, Mair e Poguntke, 2012), o que seria preocupante porque as filiações são consideradas insumos cruciais para a produção e a reprodução dessas instituições (cf. Lawson, 1980; Scarrow, 1996, 2015; Ware, 1996; Gunther e Diamond, 2001; Webb, Farrel e Holliday, 2002) ${ }^{5}$.

Dessa forma, aceito como um fato indisputável, o declínio das filiações partidárias vem sendo escrutinado com a finalidade de detectar suas variáveis

\footnotetext{
${ }^{5}$ Alerta para a saliência desse fenômeno, a editoria da revista Party Politics, a mais especializada nos estudos partidários, chegou a organizar um número especial, em 2004, com o intuito de analisar o tema mais detidamente.
} 
UMA TIPOLOGIA DO RECRUTAMENTO PARTIDÁRIO

explicativas e seus significados no contexto das democracias contemporâneas. A propósito disso, estabeleceu-se a conviç̧ão de que a redução do ativismo e da participação intermediada pelas organizações partidárias é negativa para a democracia, especialmente porque ela implica o enfraquecimento da conexão entre a sociedade e o Estado (Scarrow, 1996; Dalton e Wattenberg, 2000; Webb, Farrel e Holliday, 2002; Mair, 2005; Whiteley, 2011; Van Biezen e Poguntke, 2014). Tradicionalmente, os pesquisadores pressupõem que a ligação dessas duas esferas é proporcionada pelos partidos, organizações que, segundo sua perspectiva, devem manter vínculos sociais. Logo, se tais vínculos falharem, como parece que tem falhado, a funcionalidade do próprio sistema representativo estará ameaçada. Para alguns estudiosos, essa falha resulta do processo de "extinção" dos partidos de massas (cf. Katz e Mair, 2009).

Conforme descrito por Durverger (1951), os partidos de massas emergiram no contexto da transformação ambiental da segunda metade do século XIX, provocada pela ampliação do sufrágio. Em oposição ao partido de quadros, o partido de massas tem origem societária e depende sensivelmente das filiações em grande escala. Isso porque tais filiações suprem três necessidades incontornáveis desse tipo partidário: (a) garantir o financiamento de suas atividades por meio das contribuições dos membros; (b) obter maior penetração no tecido social, a fim de promover a socialização política e a doutrinação da classe trabalhadora; e com isso (c) possibilitar a conquista da fatia majoritária do eleitorado para chegar ao poder. Portanto, em busca de financiamento, militância e voto, o partido de massas terá se estruturado como uma organização orientada ao recrutamento integral, ou seja, à busca de novos membros para promover sua formação política e, assim, capacitá-los para sua futura atuação como quadros permanentes destinados à militância e, em alguns casos, à direção e à candidatura a cargos no Legislativo e no Executivo.

Quando então catalogou as principais características do partido de massas, Duverger (1951) observou que esse tipo de partido havia se tornado o mais bemsucedido na "luta pela vida" naquele ambiente eleitoral bastante competitivo da primeira metade do século $X X^{6}$. Seu êxito poderia induzir os concorrentes a adotar o mimetismo como estratégia adaptativa, e, consequentemente, determinados partidos de quadros se sentiriam compelidos a incorporar, pelo menos parcialmente, algumas características dos partidos de massas. Já aqueles que não conseguissem se adaptar, ou pereceriam ou ficariam relegados ao segundo plano no habitat político da época. Enfim, o partido de massas constituir-se-ia no mais eficiente modelo organizacional do período e, com isso, sua modalidade de recrutamento integral e sequencial (filiação $\rightarrow$ formação de quadros $\rightarrow$ seleção de dirigentes/burocratas/candidatos) seria vislumbrada como a estratégia mais indicada para a renovação das lideranças. Com efeito, essa modalidade de recrutamento tornar-se-ia predominante até o início dos anos 1970 (Scarrow, 2015).

Desde então o partido de massas converteu-se em algo muito maior do que um

\footnotetext{
${ }^{6}$ Para uma análise dos fundamentos evolucionistas da teoria estrutural-funcionalista dos partidos proposta por Duverger, assim como dos seus aspectos metodológicos e conceituais, conferir Peres (2009).
} 
PAULO PERES; AMANDA MACHADO

tipo descritivo de organização que corresponde a um dado contexto ambiental. Praticamente toda a linha de estudos partidários passou a considerá-lo um tipo normativo a ser seguido em qualquer país (Katz e Mair, 2009). Em outras palavras, o partido de massas foi percebido como o ponto final de uma evolução teleológica das organizações partidárias em democracias, e, como tal, ele mesmo veio a ser um dos principais indicadores da efetividade e da qualidade do regime democrático (cf. Mainwaring e Scully, 1995; Mainwaring, 1999). Por extensão, sua modalidade de recrutamento, com elevado número de filiados e formação política intensiva de seus quadros, tornou-se uma variável fundamental na aferição da saúde e da longevidade dos sistemas representativos. Justamente por causa disso, a detecção de um novo tipo partidário, em meados dos anos 1960, cujos traços característicos pareciam distanciar-se sensivelmente do partido de massas, contribuiu para dar início ao debate sobre a crise dos partidos. Tratava-se do catch-all party.

Descrito por Kirchheimer $(1966)^{7}$ com demarcado pessimismo, o partido catch-all correspondia a mais uma etapa evolutiva das organizações partidárias em resposta à intensificação da competição política. Isso significava que sua fisiologia e seu comportamento adaptaram-se às condições sociais profundamente diversas daquelas que deram ensejo à "seleção ambiental" do partido de massas. O surgimento dos grandes meios de comunicação, a proliferação de legendas partidárias, as profundas mudanças nas preferências políticas e nos valores das novas gerações tornavam necessária uma estrutura organizacional mais reduzida, pragmática e focada quase exclusivamente na disputa eleitoral. Resultado: esse ambiente "selecionou" um novo tipo de partido que, aos olhos de Kirchheimer, era repleto de contradições em relação às bases do regime democrático - os programas, as políticas e os discursos dos partidos mostravam-se cada vez mais convergentes, levando ao aumento da indiferença partidária; as filiações, por sua vez, perderam a importância que tinham, assim como as demais etapas do recrutamento integral, visando à formação de quadros no interior da organização. 0 partido "pega-todos" estava aberto a filiados dos mais variados naipes ideológicos e origens sociais; estava aberto àqueles que quisessem se filiar apenas para concorrer aos cargos eletivos; estava despreocupado, portanto, com a formação interna de quadros. Isso acarretará impactos crescentes na capacidade dos partidos de manterem vínculos sociais e elevado nível de identificação dos eleitores em relação às suas plataformas. Impactos igualmente importantes e incrementais nas taxas de filiação partidária seriam sentidos nos anos subsequentes.

Esse quadro de redução das filiações sofrerá um agravamento com a exacerbação da evolução do partido catch-all para o próximo estágio organizacional, que culminará no que Katz e Mair (1995, 1996, 2002, 2009) chamaram de cartel party. Embora do ponto de vista conceitual seja contestável a alegação de que o termo "cartel"

\footnotetext{
7 Esse texto clássico foi traduzido para o português somente em 2012, trazendo uma breve nota introdutória e notas explicativas que o contextualizam historicamente e analisam aspectos conceituais debatidos pelo autor. Conferir: Kirchheimer (2012).
} 
UMA TIPOLOGIA DO RECRUTAMENTO PARTIDÁRIO

possa ser aplicado a um tipo de partido $^{8}$, é razoável a percepção de que, nas últimas décadas, essas organizações deixaram de se importar com sua relação com a sociedade para se concentrar na captura dos aparelhos estatais visando à extração de recursos indispensáveis à sua sobrevivência. Os gastos operacionais das organizações partidárias ficaram muito elevados para os filiados individuais custeá-los, o que as obrigou a "caçar" tais recursos em outro lugar - nomeadamente, o Estado. Para serem efetivos nesse comportamento "parasita", para usarmos uma metáfora biológica bastante aplicável ao caso em questão, os partidos chegaram "espontaneamente" a um acordo cooperativo tácito de competição em que todos ganham alguma coisa, só que em graus variados um equilíbrio de Nash, como observado pelos próprios autores. Nesse cenário, a competição eleitoral cumpre a função de determinar não a vitória de apenas um contendor num jogo de soma-zero, mas sim a quantidade de recursos estatais que cabe a cada um dos partidos em competição; ou seja, quem pode ocupar os cargos executivos, legislativos e na burocracia das diversas instâncias da organização do Estado, que políticas serão contempladas de acordo com a distribuição dos votos e do poder representativo de cada um, quais os ganhos marginais a serem obtidos por meio da participação numa coalizão e assim por diante.

Em democracias com desenhos constitucionais pluralistas marcadamente fragmentadores, esse acordo distributivo é ainda mais incentivado, pois há vários recursos a compartilhar. Os partidos tenderão a utilizar os meios estatais (regras, cargos e verbas) para moderar a disputa excessivamente agressiva do tipo the-winner-takes-itall e assim garantir vantagens comparativas na disputa eleitoral. Surgirão, desse modo, determinados padrões de conluio entre as organizações partidárias, levando a um processo de competição cooperativa que visa à captura coletiva, não obstante assimétrica, dos bens públicos. Paralelamente, os partidos ficam cada vez mais dependentes da legislação produzida pelo governo, de maneira que a sociedade deixa de ser a força motriz do sistema partidário em face de sua orientação para o Estado (Katz e Mair, 2009; Whiteley, 2011; Scarrow, 2015). Isso significa que o perfil organizacional dos partidos não está mais atrelado às mudanças sociais, mas aos incentivos institucionais (Katz e Mair, 1995, 1996, 2002) ${ }^{9}$. Dessa maneira, a excessiva orientação para o Estado resultaria no afastamento do sistema partidário em relação à sociedade, tendo como provável consequência as crescentes reduções das identificações partidárias, do comparecimento eleitoral e das filiações - fatos corroborados em investigações subsequentes (Mair e Van Biezen, 2001; Dalton e Wattenberg, 2002; Mair, 2006).

\footnotetext{
${ }^{8}$ Os próprios autores reconheceram que essa denominação não foi a mais adequada (Katz e Mair, 2009). As principais críticas conceituais foram apresentadas por Koole (1996) e Kitschelt (2000) e as réplicas foram dadas por Katz e Mair (1996, 2009) e Blyth e Katz (2005).

${ }^{9}$ Katz e Mair (2009) admitem que Kirchheimer (1957) foi o pioneiro na percepção da formação do cartel partidário, algo também apontado por Krouwel $(2003,2006)$. Os autores reconhecem, ainda, que o impacto das instituições políticas da esfera estatal nas organizações partidárias já havia sido percebido pelo autor. Porém, salientam que sua descrição do tipo cartel party avançou mais profundamente na redução do peso das variáveis sociológicas e refinou os instrumentos conceituais para a detecção dos efeitos do aumento da importância do que chamaram de party-in-public-office em detrimento do party-on-theground.
} 
Conforme mostraram algumas pesquisas, a denominada cartelização exigiu mudanças organizacionais que alteraram não somente o padrão de recrutamento como também o perfil dos filiados e de seu comportamento enquanto militantes (cf. Scarrow, 2015; Whiteley, 2011). Para esse tipo de partido, os filiados deixam de ter relevância e as linhas demarcatórias entre os membros, de um lado, e os simples apoiadores e simpatizantes, de outro, tornam-se tênues; o que, por sua vez, reduz os vínculos dos militantes com a organização. Graças às drásticas mudanças ambientais dos últimos anos, provocadas pelas novas formas de contato com essas organizações, como as redes sociais da internet, blogs, sites, twitter etc., há agora múltiplas modalidades de militância e, portanto, de adesão (Whiteley, 2011). Trata-se do que Scarrow (2015) chamou de filiação multi-speed, ou seja, de várias formas de envolvimento com a organização, sendo algumas delas bastante alternativas, abertas àqueles que não querem se engajar tão profundamente nas ações partidárias. Desse modo, é crescente o número de "militantes online" e ocasionais nessa dinâmica de adesão e participação digital, mais acessível, porém, centralizada. Coexistem então formas tradicionais de ligação com os partidos, como o envolvimento diário que demanda participação intensa e cumprimento de obrigações, e formas alternativas, como no caso dos cyber-membros, cujo ativismo é facultativo, episódico e virtual. Coexistem, também, formas de participação alternativas às filiações, como é o caso dos simpatizantes digitais que seguem as redes sociais dos partidos e daqueles indivíduos que apenas acompanham as informações divulgadas nas redes e blogs associados às legendas.

A filiação multi-speed pode provocar alterações tanto na estrutura organizacional como no padrão de relacionamento da base com o partido e seus dirigentes, pois reconfigura os espaços e funções atribuídos aos membros, com impactos nos procedimentos necessários para filiação e ascensão aos postos de liderança. Por suposto, esse conjunto de elementos estabelece quem tem poder de decisão, se um grupo reduzido, um grupo ampliado ou todos os membros, o que implica maior ou menor grau de responsividade da direção perante sua base partidária (cf. Norris et al., 1990; Norris, 2000; Gunther e Diamond, 2001; Scarrow, 2015). Scarrow (2015), todavia, percebe essa dinâmica com algum otimismo, pois alega que essa multiplicidade de formas de filiação e participação permite compensar o declínio dos membros tradicionais. Na verdade, segundo ela, quando contemplado por esse prisma, pode-se observar que houve aumento no ativismo, especialmente em virtude dos simpatizantes, que são os novos militantes que se aventuram nas inovadoras modalidades de participação.

De qualquer modo, os pesquisadores convergem na conclusão de que, embora os padrões de recrutamento não sejam uniformes, pois variam consideravelmente entre os países (Norris, 2000; Kölln, 2016) ${ }^{10}$, a redução do número de filiados é uma mudança

\footnotetext{
${ }^{10}$ No Brasil, o volume das filiações varia de acordo com a proximidade das eleições, principalmente as municipais (Speck, 2014). O número de candidaturas permitido e o quociente eleitoral são importantes incentivos para o aumento desse volume, que se tornou ainda mais acentuado nos últimos anos. Segundo os dados oficiais de 2013, o total de filiados aos partidos no país era de 15 milhões, cerca de $11 \%$ do eleitorado nacional, um montante expressivo.
} 
UMA TIPOLOGIA DO RECRUTAMENTO PARTIDÁRIO

tanto quantitativa como qualitativa, que impacta interna e externamente a organização (Scarrow e Gezgor, 2010, Whiteley, 2011; Scarrow, 2015). Em primeiro lugar, a baixa filiação na modalidade tradicional indica a crise do modelo de organização partidária que prevaleceu até há poucos anos - o partido de massas (Whiteley, 2011; Scarrow, 2015). Em segundo lugar, a captura do Estado pelo chamado "cartel partidário" dispensa investimentos intensivos com o recrutamento de membros, especialmente aquele que envolve a formação política de quadros no interior da organização. A renovação das lideranças torna-se cada vez mais voltada à atração de indivíduos já formados em outras organizações ou que tenham qualquer capital político próprio - como apelo popular, família com tradição política, dinheiro, prestígio - que thes assegure vantagens comparativas para disputar eleições.

Outro ponto de convergência dos analistas é a concepção de que as formas de recrutamento estão diretamente associadas aos tipos partidários que acreditam ter se desenvolvido em cada ambiente político. Em outras palavras, o perfil do recrutamento corresponde às estratégias que cada tipo de organização, em face das circunstâncias ambientais, eleitorais e institucionais, adota para garantir sua sobrevivência num habitat profundamente competitivo e em constante mutação ${ }^{11}$. De acordo com esse raciocínio, os partidos de massas caracterizam-se pelo recrutamento integral, pois buscam, de maneira intensiva, atrair novos filiados com a finalidade de promover sua formação política e selecionar alguns deles para posições de liderança ou no quadro burocrático no interior da organização. Já os partidos catch-all foram mais pragmáticos no que se refere ao perfil ideológico dos novos membros e menos dedicados ao seu treinamento para a militância. O cartel party, por sua vez, exacerbou tais características, investindo no recrutamento de membros diretamente para a disputa eleitoral, sem qualquer preocupação com sua formação ou comprometimento ideológico. Similarmente, especializou-se na busca de meros apoiadores, sem a necessidade de vínculos de filiação.

Em linhas gerais, concordamos que, atualmente, existem novas e diversas formas de militância que dispensam os vínculos tradicionais de filiação, o que demanda análises mais refinadas do processo de recrutamento e de participação política no interior das organizações partidárias. Também concordamos com a concepção de que os perfis organizacionais e, por consequência, as estratégias de recrutamento evoluem em resposta aos ambientes interno e externo dos partidos - ideia originalmente trazida por Duverger (1951). Porém, divergimos do usual enquadramento dessa dinâmica de acordo com os tradicionais tipos partidários. Isso porque, em nossa perspectiva, tais tipos, além de demasiadamente estanques, estão assentados na enganosa premissa de que há ou deveria haver uma simetria evolutiva das organizações partidárias. Afora o desencontro com o teor epistemológico original adotado por Duverger (1951) em sua teoria

\footnotetext{
11 Não se trata aqui de postular uma relação causal direta entre perfil organizacional e tipo de recrutamento e tampouco de afirmar peremptoriamente que todos os autores seguiram esse caminho. Isso porque é impossível distinguir se o perfil organizacional "causa" o tipo de recrutamento ou o contrário. Hipoteticamente, o tipo de recrutamento é uma estratégia que tanto sofre impactos da estrutura organizacional como provoca impactos nessa mesma estrutura.
} 
PAULO PERES; AMANDA MACHADO

evolucionária sobre os partidos, as características previstas pelos tipos canônicos discrepam do plano empírico, parcial ou totalmente. De fato, da maneira como foram construídos e aplicados - indutiva e normativamente -, os tipos partidários engessaram e enviesaram as análises. No caso do engessamento, a imediata adesão aos tipos tradicionais levou os pesquisadores, antes de qualquer coisa, a sempre tentarem identificar o tipo partidário predominante em cada ambiente e, por extensão, as estruturas organizacionais desviantes. Assim, as observações desconsideram que cada partido interage de maneira diversa com os fatores ambientais específicos e que isso corresponde a uma solução adaptativa ao ambiente, cabendo ao analista apenas o estudo explicativo dessas reações contextualizadas. No caso do viés das análises, como a construção tipológica foi indutiva, a base observacional dos tipos partidários consistiu em alguns casos singulares de poucos países europeus, de forma que sua generalização empírica corre o risco de ser falaciosa.

Além disso, conforme já assinalado, o tipo partido de massas acabou sendo alçado à categoria de ideal normativo a ser seguido e, em consequência, transformou-se, ele mesmo, num indicador de desenvolvimento político. Por extensão, a abordagem orientada aos tipos partidários supõe que a evolução organizacional deveria seguir uma linearidade que, na prática, não ocorre - nem todos os partidos de um mesmo sistema poderão ser rotulados com base num único tipo, tampouco um partido que porventura seja classificado como exemplar de um tipo reúne todas as características desse tipo e, ao mesmo tempo, não apresenta nenhuma característica de outro tipo, o que quer dizer que os tipos não satisfazem os critérios de exaustividade e exclusividade. O que ocorre é precisamente o inverso, os partidos podem combinar características de dois ou mais tipos e, desse modo, se forçosamente enquadrados na rígida tipologia partidária canônica, diversos partidos, se não todos, serão "ornitorrincos" - de fato, essa é a percepção predominante na literatura a respeito dos partidos latino-americanos, especialmente os brasileiros. Mesmo no caso europeu, o "desvio" dos partidos em relação ao ideal partido de massas é visto como um processo degenerativo e não como um processo adaptativo racional e plenamente compreensível; sem mencionar que, talvez, aquele que sempre foi considerado o verdadeiro partido de massas, o Partido Trabalhista inglês, sequer tenha realmente cumprido todos os requisitos de enquadramento nesse tipo (Webb, 1995).

Aliás, aqui é importante chamar a atenção para um equívoco comum na literatura comparada. A tipologia dos partidos não é baseada no tipo ideal nos moldes weberianos, como algumas vezes se acredita. O tipo ideal weberiano é um tipo lógico, dedutivo, extremado, com a finalidade de avaliar o quanto as manifestações reais distanciam-se do tipo lógico. O tipo ideal, portanto, serve de parâmetro para as análises, e por isso nunca se deve esperar que os tipos reais se enquadrem plenamente no tipo dedutivo. A tipologia dos partidos, ao contrário, segue o modelo estabelecido por Duverger (1951), que consiste em construir tipos empíricos, portanto, indutivos. O procedimento, nesse caso, é semelhante ao do taxinomista que procura novas espécies para descrevê-las em detalhes. Dessa maneira, os tipos partidários devem encontrar 
UMA TIPOLOGIA DO RECRUTAMENTO PARTIDÁRIO

corroboração empírica fiel, pois resultam de catalogações de casos concretos observados. Isso quer dizer que cada variação significativamente desviante do tipo descritivo desafia a validade da classificação. Não obstante, a literatura tem seguido caminho contrário, ou seja, quando um partido se desvia da classificação, considera-se que o problema é o partido e não a classificação. Isso ocorre porque se utilizam tipos partidários descritivos como se fossem tipologias ideais.

Por esse prisma, no que se refere às filiações, é prudente supor que os partidos combinam modalidades em diferentes graus em resposta a situações diversas e adversas, decorrentes de contextos ambientais variáveis. Sendo assim, bastaria uma organização promover recrutamento integral para ser classificada como um partido de massas? Se um partido tiver diversas características identificadas com as de um partido de massas, mas priorizar recrutamentos parciais, ainda poderia pertencer a esse tipo? Ou seria de outro tipo? Seria um partido de quadros, catch-all, profissional-eleitoral ou cartel? Ou seria um tipo híbrido? Seria um "ornitorrinco"? E se esse mesmo partido adotar modalidades diferentes de recrutamento, mesmo com grau mais elevado de recrutamento integral, seria um partido de massas ou um partido de outro tipo? Se for de outro tipo, qual seria? Ainda, no caso de estratégias mistas de recrutamento do partido, qual o nível mínimo necessário para considerar determinada estratégia predominante e, com base nisso, tipificá-lo?

De fato, essa questão da gradação das características é crucial porque, no plano empírico, os partidos costumam variar na manifestação dos atributos e apresentar qualidades que, em menor ou maior grau, fazem parte do check-list de todos os tipos catalogados. Evidentemente, para tentar solucionar o problema da indeterminação empírica do tipo partidário derivado de um construto indutivo, alguém poderia sugerir o abandono dos indicadores dicotômicos em favor de indicadores contínuos. Porém, ainda haveria o problema da indeterminação das múltiplas combinações de gradações e dos necessários subtipos que comportem todas elas - isso sem mencionar as contestáveis convenções que teriam que ser estabelecidas para fixar os graus de cada contínuo que permitiriam identificar os tipos e subtipos de maneira segura ${ }^{12}$.

Portanto, em razão dessas "anomalias empíricas" e imprecisões operacionais, adotamos a posição de que a tentativa de analisar o recrutamento tendo como parâmetro os tipos partidários não é o caminho teórico e metodológico mais indicado. Por

\footnotetext{
12 Com base numa crítica semelhante, Scarrow e Webb (2013) idealizaram um projeto coletivo para analisar, comparativamente, as organizações partidárias de diversos países. Sua proposta é superar dois enquadramentos que predominam nessa linha de pesquisa: de um lado, a preocupação com o grau de institucionalização dos partidos nas democracias recentes; de outro, a preocupação com os possíveis desvios dos partidos das democracias mais antigas em relação aos tipos catalogados. Na perspectiva desses pesquisadores, cada partido pode apresentar um desenvolvimento diferente, pois atua em contextos históricos e sociais diversos, e tem, ele mesmo, origem e trajetória próprias. Assim, em vez de procurar desvios em relação aos tipos catalogados, os analistas devem procurar entender as variações organizacionais em cada contexto, sem recorrer às tipologias rígidas e, por vezes, teleológicas. Eles propõem que os estudos comparados devem adotar indicadores que possibilitem analisar como cada partido se situa em determinadas variáveis organizacionais, mensuradas em um contínuo, e não pela simples conferência de check-lists geralmente compostos por categorias dicotômicas.
} 
PAULO PERES; AMANDA MACHADO

isso, no modelo classificatório que propomos a seguir, não é nossa intenção explorar possíveis vínculos entre essas duas variáveis - recrutamento e tipo partidário. Não é nossa preocupação avaliar se o cartel party é aquele que investe mais no recrutamento parcial, dispensando a formação de quadros, em oposição ao partido de massas, que supostamente investe no recrutamento integral, pois não consideramos producente a aplicação de tipos partidários na análise dos partidos. Acima de tudo, o que nos interessa é a adoção de um modelo de análise que apreenda os tipos ou a combinação de tipos de recrutamento adotados pelos partidos vis-à-vis os desafios ambientais a sua sobrevivência e sua estrutura organizacional. Devido a isso, propomos uma tipologia dedutiva com o intuito de possibilitar uma aproximação analítica do problema por meio de uma ferramenta heurística que seja capaz de abarcar as possibilidades lógicas de manifestação empírica do fenômeno.

\section{Especificações conceituais do modelo classificatório}

O modelo heurístico ${ }^{13}$ que propomos aqui é tipológico, o que significa dizer que se trata de um modelo dedutivo. Em linhas gerais, os modelos são reconstruções simplificadas e delimitadas da realidade, com o objetivo prático de tornar operacional a compreensão de um fenômeno que, via de regra, é complexo (Lave e March, 1975; Star, 2005). Modelos são representações conceituais produzidas por um procedimento conjectural acerca dos processos e fatos mínimos cruciais da estrutura de um dado fenômeno. Sua construção é essencialmente analítica, pois demanda a "dissecação mental" do objeto em suas partes constituintes essenciais, de modo a identificar aquelas cuja compreensão resultará no conhecimento teórico do todo (Moran, 2008; Lomnicki, 1999; Lave e March, 1975).

No que refere a raciocínio e procedimento científicos, um dos modelos mais recorrentes é o classificatório ${ }^{14}$. Em termos metodológicos, os modelos classificatórios correspondem ao primeiro passo para o entendimento de qualquer conjunto de entidades

\footnotetext{
13 Um modelo heurístico consiste num método ou num processo aplicado para a resolução de algum problema que seja complexo e caracterizado pela impraticabilidade da busca exaustiva de informações. Isso demanda a adoção de um conjunto de procedimentos visando a solucionar enigmas científicos por meio de aproximações válidas, mediante a revelação de processos que se tornarão perceptíveis em decorrência do próprio modelo de enquadramento do fenômeno (cf. Polya, 1973).

${ }^{14}$ Nas ciências sociais há uma consolidada tradição de utilização dessa abordagem (cf. Sneath e Sokal, 1973; McKinney, 1966; Tiryakian, 1968; Bailey, 1974, 1992). Seu uso disseminado se deve, principalmente, a inúmeras vantagens oferecidas pelos estudos classificatórios dos fenômenos sociais, como, por exemplo, seu poder descritivo, a simplificação da realidade, a identificação de similaridades e diferenças, a comparabilidade, a exaustividade na apreensão dos dados relativos a conjuntos e subconjuntos do objeto estudado e a facilidade na identificação das relações entre dimensões, categorias e variáveis (Sneath e Sokal, 1973; Bailey, 1994; Doty e Glick, 1994; Bowker e Star, 1999; Jacob, 2004; Gregory, 2006; Meyer, 2007). Na ciência política, os modelos tipológicos, assim como outros modelos formais, sejam matemáticos ou computacionais, são cada vez mais predominantes, a ponto de serem tão importantes quanto as teorias, inclusive porque os modelos são representações operacionais do mundo reconstruído pelas teorias (Lave e March, 1975; Clarke e Primo, 2007, 2012). Obviamente, a literatura também aponta algumas desvantagens no uso das tipologias, como se pode depreender das discussões de Bowker e Star (1999) e Chandra (2005).
} 
UMA TIPOLOGIA DO RECRUTAMENTO PARTIDÁRIO

que caracterizam o fenômeno a ser analisado porque eles dão os parâmetros para a percepção, a organização e a interpretação dos objetos observados (Diesing, 1971) ${ }^{15}$. Sinteticamente, as classificações podem ser entendidas como processos de agrupamentos de entidades por similaridade, com base na identificação de atributos discriminantes de indivíduos e grupos a partir de dimensões categóricas nominais ou ordinais. Os indivíduos devem ser agrupados de uma maneira que cada grupo seja o máximo possível diferente dos outros e que, ao mesmo tempo, contenha indivíduos que sejam semelhantes o máximo possível (Bailey, 1994). Em outras palavras, o propósito principal da classificação é a minimização da variação dentro dos grupos (homogeneidade interna) e a maximização da variação entre os grupos (heterogeneidade externa). Desse modo, ao permitir a organização estrutural das entidades de um fenômeno em agrupamentos ou classes, a lógica classificatória é uma ferramenta que potencializa a análise comparativa das unidades observadas, das relações entre as componentes de um grupo e da interação de grupos diferentes (Moran, 2008).

Para ser consistente em termos operacionais, as classificações devem seguir um arcabouço rígido de critérios de exclusividade, exaustividade e adequação (Sneath e Sokal, 1973; Bowker e Star, 1999; Jacob, 2004; Gregory, 2006). No que se refere à exclusividade, as fronteiras entre os grupos devem ser claramente demarcadas, com regras estáveis de inclusão e exclusão dos casos nos agrupamentos - o que significa que as categorias não podem se sobrepor, que devem ser mutuamente exclusivas. Quanto à exaustividade, o conjunto dos grupos deve ser abrangente o suficiente para classificar de forma completa todos os casos da observação. Em relação à adequação, as categorias devem ser facilmente aplicáveis, pois sua validade dependerá da sua capacidade de enquadramento da observação dos dados e de sua análise.

Além dos critérios para a construção das categorias classificatórias, o pesquisador deve lidar com outro aspecto operacional crucial que é a escolha das características que darão subsídios para a classificação. Como há diversas possibilidades de seleção dessas características norteadoras, o protocolo recomendado é procurar apreender os aspectos que sejam realmente relevantes para o estudo do fenômeno, de acordo com o problema proposto; algo que dependerá sensível e inevitavelmente da perspicácia do pesquisador (Lave e March, 1975; Bailey, 1994). A fim de reduzir a arbitrariedade em favor de um convencionalismo que seja rigoroso tanto quanto possível, essa tradição metodológica convergiu para um algoritmo básico. Deve-se, primeiramente, identificar o que mais interessa à pesquisa e então delimitar esse aspecto na forma de um objeto de investigação; deve-se, depois, fazer o "experimento mental" de dividi-lo em suas componentes principais e identificar os grupos ou classes de entidades de acordo com suas semelhanças e diferenças, procurando conformar um conjunto que seja exaustivo e composto de subconjuntos exclusivos; deve-se, por fim,

\footnotetext{
15 Segundo Bailey (1994, p. 1), a classificação é um exercício conceitual ubíquo, presente tanto na formação e utilização da linguagem, seja da verbal ou da matemática, como nas teorias científicas, de forma que, "without classification, there could be no advance conceptualization, reasoning, language, data analysis or, for that matter, social science research".
} 
representar graficamente a classificação num formato que corresponda à sua dimensionalidade e aplicá-lo à análise dos dados. Observe-se que, ao contrário das classificações unidimensionais, as dimensões das classificações bidimensionais e multidimensionais relacionam-se umas com as outras para formar subcategorias - tipos ou $\operatorname{taxa}^{16}$.

Em termos metodológicos, as classificações podem se basear em sistemas de inferências tanto indutivos como dedutivos. A reunião de diversos casos singulares observados no plano empírico, com a finalidade de catalogar características distintivas para agrupar indivíduos semelhantes e, a partir daí, propor tipos que rotulem os grupos, caracteriza a inferência indutiva. Esse protocolo de pesquisa é o taxonômico e sua base constitutiva é essencialmente empírica (Bailey, 1994; Doty e Glick, 1994; Chandra, 2005). Isso significa que as classificações indutivas demandam o levantamento do máximo de informações disponíveis da maneira a mais exaustiva possível, uma vez que elas são sua síntese compreensiva. Os dados utilizados podem ser oriundos de informações primárias ou secundárias. Uma vez aceitas, tais taxonomias orientam estudos posteriores dos exemplares empíricos das entidades catalogadas ${ }^{17}$.

Por sua vez, as classificações que adotam a inferência dedutiva se baseiam em procedimentos lógicos, essencialmente teóricos, anteriores portanto à observação de casos singulares (Bailey, 1972, 1973, 1994). Isso geralmente ocorre quando há pouca ou nenhuma informação disponível ou quando a pretensão é esgotar logicamente as possibilidades de manifestação empírica de um fenômeno para enquadrar o levantamento e a análise de informações em categorias apriorísticas. Com o foco assim delimitado logo de partida, aumenta-se a eficiência da coleta e da análise dos dados (cf. Clarke e Primo, 2007, 2012) ${ }^{18}$. Epistemologicamente, os modelos dedutivos são considerados mais analíticos, pois a abstração e a simplificação dos fenômenos, no geral, complexos, envolvem a separação de suas componentes fundamentais para resolver algum problema prático de investigação que demanda sua redução a poucas categorias que lidem com um conjunto delimitado de variáveis. Devido a esse procedimento, as generalizações dos modelos dedutivos são consideradas mais acuradas, uma vez que sua lógica de inferência consiste na identificação dos princípios recorrentes ou no esgotamento lógico das possibilidades empíricas do fenômeno estudado. Ainda, as classificações dedutivas, que são modelos lógicos, não podem ser testadas

\footnotetext{
${ }^{16}$ Os tipos correspondem às classificações tipológicas, construídas por inferência dedutiva. Já os taxa (em latim, plural de táxon, que é uma unidade taxonômica) correspondem às classificações taxonômicas, construídas por inferência indutiva.

17 As análises de cluster, por exemplo, são procedimentos quantitativos de inferência indutiva, pois recorrem à metodologia estatística para encontrar agrupamentos a partir de uma vasta base de dados. Também há exemplares de classificações indutivas qualitativas, como os estudos sobre as organizações partidárias - desde Duverger (1951), formou-se toda uma linha de estudos voltada à descrição das variações morfológicas e fisiológicas de suas estruturas organizacionais para a identificação de tipos. Embora essa catalogação seja conhecida como tipologia partidária, em termos mais rigorosos, podemos dizer que se trata de uma taxonomia partidária.

${ }^{18}$ Ademais, modelos dedutivos são percebidos como a solução mais sustentável do problema da indução, apontado por Hume, e que levou Karl Popper a propor como modelo científico o método hipotéticodedutivo de teste (Popper, 1959).
} 
UMA TIPOLOGIA DO RECRUTAMENTO PARTIDÁRIO

empiricamente - em primeiro lugar, porque a pesquisa não é desenhada para testar o modelo, mas, no máximo, conforme o caso, testar alguma hipótese derivada de uma teoria; em segundo lugar, porque a classificação dedutiva não é uma explicação do fenômeno, mas sim sua reconstrução simplificada. Não obstante, uma classificação dedutiva pode e deve ser avaliada pela sua consistência estrutural e sua adequação ao estudo do objeto (cf. Collier, LaPorte e Seawright, 2012) ${ }^{19}$, ou seja, pelas suas anomalias lógicas e empíricas ${ }^{20}$.

De modo mais delimitado, podemos dizer que os modelos classificatórios dedutivos são tipológicos (Lazarsfeld, 1937; Lazarsfeld e Barton, 1951; Hempel, 1952; Doty e Glick, 1994; Moran, 2008). Por sua vez, as tipologias são conjuntos de tipos construídos logicamente para representar uma combinação de atributos específica que descreve analiticamente algum fenômeno. Enquanto um construto conceitual, assim como ocorre com qualquer classificação, as tipologias devem definir cada tipo de maneira precisa, de acordo com os mesmos critérios de categorização já aludidos - adequação (validade, simplicidade), exaustividade, exclusividade. Também devem ser parcimoniosas, ou seja, devem conter uma gama reduzida de tipos que sejam facilmente compreendidos e distinguíveis (Meyer, 2007). Devem, ainda, ter um foco preciso para cumprir a precípua função operacional de discriminar o que é relevante à observação e análise, uma vez que os tipos devem enquadrar casos empíricos segundo a correspondência dos atributos (Kluge, 2000; Jacob, 2004). Para tanto, os dados são coletados e organizados com base numa pergunta diretriz central: tal caso se enquadra em qual tipo?

Em termos operacionais as tipologias promovem enquadramentos categóricos multidimensionais, cujos rótulos geralmente são dispostos numa matriz que combina duas ou mais dimensões. O procedimento protocolar para sua construção tem a sequência: conceito geral $\rightarrow$ dimensões $\rightarrow$ variáveis $\rightarrow$ tipos. Em virtude da estrutura classificatória que assegura às análises empíricas, as tipologias permitem estudos comparativos, inclusive longitudinais, apontando semelhanças, diferenças, permanências e mudanças. Também fazem a ligação dos dados com a teoria, sejam eles qualitativos ou quantitativos. Desse modo, as tipologias cumprem três funções metodológicas relevantes (cf. Collier, LaPorte e Seawright, 2012): a primeira é analítica e consiste na fragmentação do objeto em partes ou grupos e subgrupos, de modo a enquadrar cada caso num tipo e detectar as relações entre os tipos; a segunda é descritiva, pois recorre à catalogação dos atributos de cada tipo ou conceitos compostos, com o propósito de caracterizar cada caso; a terceira função é explanatória, pois possibilita a antecipação das futuras relações entre tipos e casos que serão observados, ou seja, a previsão do

\footnotetext{
${ }^{19}$ A adequação corresponde à sua capacidade de permitir a observação estruturada do fenômeno, a coleta dos dados e a análise das informações por um enquadramento conceitual delimitado e verossímil, o que permitirá a apreensão das informações de maneira seletiva e categorizada (Clarke e Primo, 2007, 2012). ${ }^{20} \mathrm{Se}$ utilizarmos os termos kuhnianos, as "anomalias" das classificações dedutivas podem ser de dois tipos: a lógica e a empírica (Kuhn, 1962). A anomalia lógica tem a ver com a consistência e a coerência do modelo; a empírica, com sua inadequação à apreensão do objeto, sua inaplicabilidade ou insuficiência para o enquadramento descritivo do fenômeno ou de sua parte que está sob investigação classificatória.
} 
funcionamento do objeto classificado.

São duas as variações consagradas de tipologias: os tipos ideais e os tipos descritivos. Os tipos ideais são "puros" - tipos lógicos extremados que não encontram plena correspondência no plano empírico, pois o que se procura nesse caso é apenas um parâmetro para a identificação de exemplares singulares do fenômeno por meio da detecção de traços mais ou menos aproximados das características previstas logicamente. Os tipos ideais servem de esquadro, digamos assim, para avaliar o distanciamento dos fenômenos reais em relação à perfeição do "caráter utópico" do tipo lógico puro ${ }^{21}$. Embora sua construção também seja lógica, as tipologias descritivas, por sua vez, cumprem o propósito de retratar as possibilidades empíricas factíveis dos fenômenos. Dito de outro modo, as tipologias descritivas não consistem na proposição de características puras e extremadas, mas sim na antecipação lógica e apriorística de elementos que de fato se espera encontrar no plano empírico.

O modelo classificatório que propomos a seguir é dedutivo, portanto, tipológico. Mais especificamente, trata-se de uma tipologia descritiva. Para sua construção, adotamos os critérios discutidos nesta seção. Consequentemente, seguimos o protocolo sequencial de construção dos tipos, partindo do conceito geral de recrutamento partidário, identificando suas dimensões (filiação, treinamento e seleção de elites) e suas variáveis (tipos, subtipos, modalidades, formas e meios). Deve ser ressaltado adicionalmente que, assim como ocorre com toda classificação, o modelo que propomos é aberto a ajustes, tais como modificações, acréscimos e reduções. O Fluxograma 1 contextualiza de maneira sintética o percurso metodológico que seguimos para a construção do modelo tipológico.

\footnotetext{
${ }^{21}$ Max Weber é o representante mais destacado na proposição e no uso dessa variação de modelo tipológico, como mostram seus estudos exemplares acerca do desenvolvimento do capitalismo e das religiões. Essencialmente, esse é um procedimento marcadamente platônico de separação entre o mundo inteligível e o mundo sensível.
} 


\section{Fluxograma 1 \\ Síntese da fundamentação do modelo tipológico}

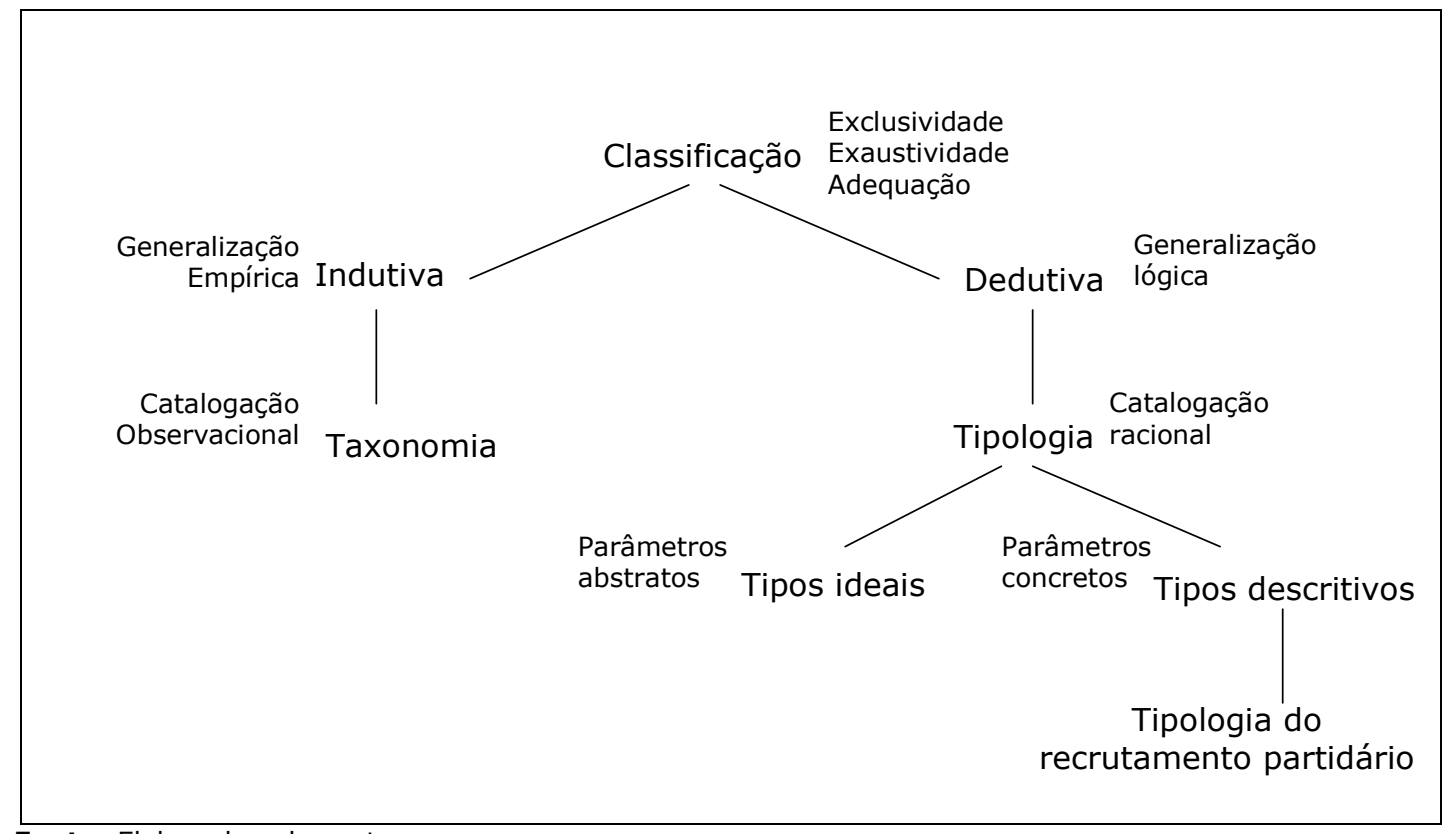

Fonte: Elaborado pelos autores

\section{Modelo tipológico do recrutamento partidário}

\section{Definição conceitual}

Nossa definição conceitual de recrutamento partidário é abrangente o suficiente para abarcar a totalidade de manifestações desse fenômeno em suas diversas dimensões. Consideramos que o recrutamento partidário é um processo que pode ser decomposto logicamente em três aspectos: (A) filiação; (B) formação de quadros e (C) seleção de membros para a ocupação de cargos de importância para o partido, seja na burocracia organizacional ou estatal, seja para a candidatura a cargos eletivos e, eventualmente, o exercício de tais funções ${ }^{22}$. Assim, os tipos, subtipos, formas, meios, modalidades e submodalidades de recrutamento compõem um portfólio de combinações à disposição dos partidos para que estes recorram àquelas que julgarem as mais indicadas ou viáveis para cada situação ou contexto do ambiente político.

\footnotetext{
${ }^{22}$ Os postos mais importantes a serem ocupados pelas lideranças recrutadas, em princípio, são os seguintes: (1) cargos na burocracia partidária; (2) cargos na burocracia estatal passíveis de serem preenchidos sem concurso; (3) cargos na direção partidária; (4) vaga como candidato a algum cargo eletivo de maior relevância (em especial para o Executivo e o Senado) e (5) cargos eletivos conquistados pelo partido.
} 
No nosso modelo, há dois tipos de recrutamento: extensivo e intensivo ${ }^{23}$. Se um partido investir de maneira sequencial nos três processos do recrutamento ou nas duas primeiras etapas, teremos uma organização que intenciona atrair novos membros para dar-lhes formação política, mediante treinamento teórico e/ou prático, visando à atuação futura de alguns deles como políticos profissionais. Dessa maneira, esse tipo de recrutamento é orientado à formação política dos filiados, podendo alguns deles chegar às posições de liderança e aos quadros burocráticos. Em ambos os casos - recrutamento integral e recrutamento parcial com formação - o ponto mais importante é a educação política e a doutrinação dos membros. Podemos então dizer que se trata de recrutamento extensivo, pois é alongado, amplo, extenso, dilatado, por meio do qual se processam a formação dos filiados e a seleção de alguns deles para candidaturas ou cargos burocráticos dentro ou fora do partido.

Dessa maneira, a despeito do maior esforço e dispêndio de recursos, um partido pode investir no recrutamento extensivo em decorrência de seus objetivos e de sua inserção ambiental. Nesse caso, o recrutamento partidário não se reduz à filiação ou à busca de candidaturas, pois a formação, enquanto uma etapa intermediária, é considerada extremamente importante para que os quadros sejam qualificados antes de assumirem qualquer posição de maior hierarquia na organização. É provável que isso ocorra porque o partido tem a pretensão de formar militância e lideranças que realmente sejam comprometidas com seu programa e sua ideologia. Consequentemente, espera-se que as lideranças gozem de grande legitimidade perante os membros da base, da burocracia e da direção. Os dois caminhos ou subtipos de recrutamentos extensivos são os voltados à formação de lideranças para seleção e os destinados à formação de militância.

Porém, um partido pode investir num tipo de recrutamento que dispensa a formação política de quadros. Nesse caso, podemos chamá-lo de recrutamento intensivo, que consiste num esforço concentrado, mais pontual e de curta duração, que investe em um - apenas filiação - ou dois aspectos desse processo - filiação e seleção. Para tanto, há dois caminhos possíveis, referentes aos subtipos do recrutamento intensivo. No primeiro deles não é necessário que todos os filiados sejam formados politicamente no interior da organização com vistas à ocupação posterior de alguma posição de liderança ou no quadro burocrático. Dessa maneira, um partido pode atrair membros já formados em uma instituição exógena ou então uma figura popular por qualquer razão, sem nenhuma formação política prévia mais relevante. Geralmente essa modalidade de recrutamento é orientada a candidaturas ou ao aumento das bancadas legislativas e executivas. O segundo caminho reduz-se pura e simplesmente à filiação, configurando

\footnotetext{
${ }^{23}$ Esses termos foram adotados com base na sua semântica e sua etimologia.
} 
UMA TIPOLOGIA DO RECRUTAMENTO PARTIDÁRIO

uma estratégia de recrutamento orientada à ampliação da base partidária ${ }^{24}$.

Por não contemplar a formação política interna à organização, o recrutamento intensivo exige menor investimento de recursos materiais e de tempo. Obviamente, um partido pode adotá-lo não apenas por causa da economia de recursos e esforços, mas também por ser esse um recrutamento estratégico em face do ambiente político e dos seus objetivos. Nesse caso, as duas orientações do recrutamento intensivo podem ser combinadas em doses diferentes ou utilizadas de maneira alternada ao longo do tempo. Um partido pode, por exemplo, investir mais pesadamente no recrutamento intensivo orientado às candidaturas/lideranças e dedicar menor investimento ao recrutamento intensivo orientado à militância e à base. Porém, em períodos eleitorais, esse mesmo partido pode aumentar seu investimento no recrutamento intensivo orientado à base, com a intenção de aumentar o suporte de sua campanha e seu montante de votos. Ainda, seu investimento no recrutamento intensivo orientado às candidaturas provavelmente será maior em períodos pré-eleitorais.

Portanto, as combinações, magnitudes e temporalidades das orientações do recrutamento intensivo serão o resultado das estratégias partidárias e devem ser entendidas de acordo com a configuração de cada ambiente político. Conforme a necessidade e a viabilidade, o partido poderá adotar como estratégia a atração de membros para a campanha eleitoral ou alguma outra forma de apoio às suas atividades rotineiras. Dependendo da situação, para as ações de maior relevância, o partido procurará atrair lideranças já formadas em outras instituições, como sindicatos, ONGs, movimentos sociais e estudantis, demais organizações partidárias e todas as diversas formas de associações civis. Ou então o partido poderá tentar atrair outsiders do sistema de representação de interesses. Em suma, se é indispensável que toda liderança ou quadro burocrático seja um filiado, não segue disso que todos os filiados terão de ser formados politicamente pelo partido ou virão a ser lideranças ou mesmo componentes da burocracia partidária ${ }^{25}$.

Já num partido em que predomina o recrutamento extensivo será rara a existência de candidaturas de outsiders ou de indivíduos com formação em outras instituições. A maioria ou a totalidade das poucas exceções que podemos esperar para a existência residual de um recrutamento intensivo num partido com recrutamento predominantemente extensivo deve corresponder à atração de pessoas ligadas a movimentos sociais, sindicatos, ONGs e congêneres. É de esperar que existam militantes com trajetória de formação política paralela no partido e na outra instituição externa,

\footnotetext{
${ }^{24}$ Esse subtipo de recrutamento, intensivo orientado à base, abrange algumas das filiações e militância multi-speed identificadas por Scarrow (2015).

${ }^{25}$ Uma questão que se coloca para possível investigação, com base nesse ponto, é a de saber se o partido sofreria consequências negativas de médio e longo prazos se investir toda sua estratégia de renovação unicamente no recrutamento intensivo. Isso porque a literatura, de modo geral, concorda que parcela substantiva da renovação dos quadros partidários dependerá, forçosamente, do recrutamento de jovens que deverão ser atraídos para o treinamento para a militância e a dedicação profissional à política, seja como dirigente no interior da organização, seja como ocupante de cargo representativo ou na burocracia estatal.
} 
mas poucos que tenham uma trajetória exclusivamente externa e que só depois sejam recrutados para qualquer candidatura ou para assumir posição de liderança. Também podemos supor que serão reduzidos os casos de recrutamento de políticos eleitos por outros partidos e já formados politicamente neles - quando isso ocorrer, é mais provável que sejam partidos programaticamente próximos.

Não obstante, a expectativa da existência de alguma submodalidade de recrutamento intensivo residual em partidos que investem de maneira mais vigorosa no recrutamento extensivo mostra que, mesmo aqui, é possível combinar tipos e subtipos de recrutamento em graus variados e de maneira alternada, conforme as oscilações do ambiente político. Podemos até supor que haja uma transformação organizacional importante no partido que investe maciçamente no recrutamento extensivo quando suas lideranças ultrapassam certo limite máximo de recrutamento intensivo como parte de sua estratégia de atração de novos membros. Isso significa que a modalidade de recrutamento pode ser um dos indicadores da mudança organizacional em face da mudança estratégica em resposta ao ambiente político. Pari passu com a alteração da estratégia de recrutamento, haverá alguma mudança em seu discurso, em sua atuação eleitoral e governamental e em seu programa. Subsequentemente, haverá impactos em seus membros, com algum conflito entre suas facções internas, que reclamarão da perda do caráter formativo, militante e até programático do partido. O Quadro 1 ilustra os tipos e subtipos de recrutamento.

\section{Quadro 1
Tipos e subtipos de recrutamento partidário}

\begin{tabular}{|c|c|ccc|}
\hline \multicolumn{2}{|c|}{ Categorias } & \multicolumn{2}{c|}{ Etapas } \\
\hline Tipos & Subtipos & A & C \\
\hline \multirow{2}{*}{ Extensiva } & Formação de lideranças & Filiação $\rightarrow$ & Formação $\rightarrow$ & \\
& Formação de militância & Filiação $\rightarrow$ & Formação \\
\hline \multirow{2}{*}{ Intensiva } & Candidaturas/Bancadas & Filiação & $\rightarrow$ & Seleção \\
& & & \\
& Aumento da base & Filiação & \\
\hline
\end{tabular}

Fonte: Elaborado pelos autores.

Formas de recrutamento

A implementação das estratégias relativas aos dois tipos de recrutamento pode contemplar formas específicas de incorporação de novos membros aos partidos quanto ao escopo e à origem. Com relação ao escopo, o recrutamento pode ser fechado ou aberto; quanto à origem, ou seja, à base social de onde derivam os novos filiados, o recrutamento pode ser plutocrático ou democrático.

Quando fechado, o recrutamento se dá de maneira endógena à própria organização. Duverger (1951) falava da origem partidária interna ao sistema parlamentar para se referir aos partidos fundados por políticos já estabelecidos e 
UMA TIPOLOGIA DO RECRUTAMENTO PARTIDÁRIO

atuantes no Legislativo; aqui, nosso critério de distinção é o próprio partido. Assim, é importante distinguir aqueles que se filiam ao partido sem ter tido anteriormente qualquer ligação importante com ele daqueles que antes de se filiarem já tinham com ele alguma relação indireta. A relação indireta mais visível e relevante é a de parentesco, de modo que a forma fechada de recrutamento consiste na integração dos filhos e demais parentes próximos dos membros do partido ${ }^{26}$. Obviamente, o estabelecimento do grau mínimo de parentesco necessário para enquadrar essa forma de recrutamento dependerá sempre de convenção estabelecida pelo pesquisador. Em princípio, parentesco de primeiro até terceiro grau parece ser o escopo mais adequado, mas esse limite tem que ser justificado em cada pesquisa, de maneira contextualizada.

É importante destacar que nem todos os parentes recrutados assumirão posições de liderança. Nesse caso, parentes podem ser recrutados apenas para disputar eleições ou para compor a base do partido. Isso quer dizer que há um recrutamento fechado voltado à renovação da elite e outro voltado à incorporação de novos membros à organização, seja para o incremento da base ou para a competição eleitoral. Esses dois meios têm significados e efeitos diferentes. O recrutamento fechado-para-a-base pode evidenciar a importância que o contato indireto com o partido por intermédio de um parente filiado tem como fator motivacional para a adesão à organização; mas, do ponto de vista organizacional, seus efeitos são desprezíveis. O recrutamento fechado-para-aelite também evidencia a relevância do parentesco para a filiação ao partido, mas tem efeitos relevantes para a organização, a composição da direção e a atuação eleitoral. 0 percurso para chegar à posição de liderança, em alguma medida, será mais fácil para aqueles que não forem parentes dos dirigentes - a competição para cargos mais prestigiados e com poucas cadeiras em disputa estará reservada aos "herdeiros de sangue" da elite partidária; a tomada de decisão sobre o programa e as estratégias da legenda serão restritas aos grupos familiares.

A análise dessa forma de recrutamento é relevante porque permite identificar o volume e o peso do predomínio das famílias políticas nos partidos; permite avaliar o quanto alguns partidos são empresas familiares cujos "modelos de gestão" seguirão mais a intuição e o desiderato dessas lideranças do que os conselhos dos técnicos e assessores ou as pressões da base. Além disso, ao identificar esse tipo de recrutamento, torna-se possível traçar a trajetória desse filiado no interior da organização em comparação com os demais - se o filiado cuja família é importante dentro do partido consegue chegar mais rápido aos cargos de direção ou à seleção para candidatura a cargos mais relevantes, por exemplo. Em compensação, tais partidos poderão ter dificuldades para competir no ambiente eleitoral e renovar suas elites com pessoas que tenham

\footnotetext{
${ }^{26}$ Algumas vezes, esse caráter endógeno pode se manifestar em relação ao sistema político mais amplo, ou seja, filhos e parentes de políticos são recrutados por partidos diferentes de seus familiares. Todavia, casos como esses, provavelmente, são raros. Ademais, em princípio, o modelo que propomos pode ser expandido para que se inclua no recrutamento fechado aqueles indivíduos oriundos da mesma classe social, embora seja difícil identificá-los no contexto de partidos de composição pluralista, como parece ser a regra geral.
} 
PAULO PERES; AMANDA MACHADO

capacidade de liderança, uma vez que seguem um processo sucessório baseado na substituição dos velhos dirigentes pelos seus parentes, e estes não são necessariamente os mais indicados para assumir tais posições ou não terão o mesmo carisma da liderança anterior para manter a base partidária enquanto um grupo de seguidores. A análise também deverá identificar cada caso de maneira contextualizada.

Por sua vez, quando se trata de recrutamento aberto, o novo filiado não tem relação de parentesco com nenhum dos membros da base ou da direção. Em partidos com essa forma de recrutamento, a renovação das elites segue outros critérios que não o da herança política familiar, tais como capacidade de liderança, habilidade para negociar, simpatia, carisma, eloquência, raciocínio estratégico, senso de oportunidade, grandes realizações, prestígio, popularidade, entre outros. Nesse sentido, as novas lideranças terão que trilhar de maneira autônoma os caminhos que levam às posições de direção ou de representação eleitoral, seja no interior da própria organização ou em outra instituição, principalmente no caso de o recrutamento aberto ser extensivo, pois é o período de formação que será preponderante para a ascensão na hierarquia partidária. O recrutamento aberto-para-a-base ocorrerá por afinidade programática ou interesse pragmático, que é quando o objetivo é extrair vantagens mútuas da filiação, tais como acesso a cargos, obtenção de favores, lançamento de candidaturas, apoios para a campanha, militância ocasional ou cotidiana, e assim por diante. A gestão interna da organização estará mais propensa a interferências variadas, inclusive da burocracia e dos assessores. Os caminhos que levam às posições de liderança estarão livres à concorrência interna e à conquista dos mais habilidosos e bem relacionados na rede dos grupos internos e dos apoiadores. Mesmo um partido com essa forma de recrutamento poderá ser controlado de maneira centralizada, com a diferença de que o poder estará reunido numa elite não hereditária.

Não obstante, os partidos também podem combinar essas formas de recrutamento, o que parece ser mais realista. Um partido pode, por exemplo, promover, simultaneamente, o recrutamento aberto-para-a base e o recrutamento fechado para-aelite para suprir de maneira distinta suas posições organizacionais. Pode, ainda, recrutar de forma aberta e fechada tanto para a base como para o topo da organização, variando entretanto os respectivos graus - recrutamento aberto com maior volume para a base e com menor volume para o topo. Cada combinação será o resultado de uma estratégia de recrutamento quanto à forma e aos seus meios que corresponde às tentativas partidárias de adaptação às oscilações do ambiente político. Do mesmo modo, cada combinação terá efeitos diferenciados sobre a própria organização e sobre sua interação com o habitat.

Quanto à origem, os recrutamentos plutocrático e democrático ocorrem de acordo com a caracterização explorada por Weber (1992) a partir da dicotomia entre os políticos que vivem para a política e aqueles que vivem da política. Os políticos profissionais que dependem da política para sobreviver precisam contar com os rendimentos extraídos dessa profissão. Mesmo aqueles que por ventura "vendem" sua atuação para determinados grupos econômicos e, ao mesmo tempo, não pertencem, 
UMA TIPOLOGIA DO RECRUTAMENTO PARTIDÁRIO

inicialmente, à base social abastada, enquadram-se no recrutamento democrático. Tais políticos vêm do demos, das classes sociais menos endinheiradas, e, por isso, seu recrutamento é democrático. O recrutamento plutocrático engloba aqueles que, de início, não dependem dos rendimentos extraídos da política profissional, ou seja, dos cargos eletivos ou burocráticos que ocupam no Estado. Isso não quer dizer que os indivíduos que vivem para a política também não possam viver da política, uma vez que podem se utilizar desse meio para obter vantagens. Políticos que foram recrutados de forma plutocrática muitas vezes vivem da política não apenas porque, por intermédio dela, ampliam seu patrimônio, mas também porque essa posição lhes garante vantagens em processos judiciais e maior liberdade de ação para favorecer seus interesses sociais, morais e econômicos.

No contexto atual, devemos observar, essa distinção está cada vez mais nebulosa, pois indivíduos que entraram na política por recrutamento democrático tornaram-se ricos e, caso fossem recrutados no presente momento, enquadrar-se-iam no recrutamento plutocrático. Diante disso, para facilitar a classificação, o importante é enquadrar a forma de recrutamento em relação à base social considerando-se o momento em que ocorre a filiação ${ }^{27}$.

Os fatores distintivos mais imediatos de uma forma ou de outra de recrutamento quanto à origem são renda/patrimônio e formação/ocupação profissional. Em partidos nos quais predomina o recrutamento democrático, devemos esperar membros de classes sociais e profissionais que vão desde aqueles com níveis menores de renda e escolaridade até os que têm níveis médios-altos com formação superior e os profissionais liberais. Esses partidos tenderão a ter bem mais indivíduos das classes baixa, médiabaixa e média-média em suas fileiras, tanto na base como nas posições mais elevadas da organização. Por outro lado, em partidos nos quais predomina o recrutamento plutocrático, especialmente para sua elite, devemos encontrar um número mais elevado de membros das classes média-alta e alta, com níveis de formação superior e atuação no mundo empresarial, muitos sendo proprietários de empresas de médio e grande porte ou profissionais que atuam nessas esferas corporativas. Podemos esperar que um partido que privilegia recrutamentos plutocráticos reserve a maioria, se não a totalidade, de suas posições de direção e representação aos indivíduos oriundos das classes média-alta e alta, designando as funções de militância e de atividade burocrática aos recrutados de forma democrática, mas com um quadro reduzido de filiados na base.

Tanto os recrutamentos democráticos como os plutocráticos, em princípio, podem ocorrer por dois meios: para-a-base e para-a-elite. Contudo, é de esperar um volume muito maior de recrutamentos plutocráticos para-a-elite do que para-a-base.

\footnotetext{
${ }^{27}$ Nada impede, porém, que, a depender do interesse do pesquisador, possa ser estudada a transformação dos recrutados, ou seja, como determinadas elites políticas recrutadas de maneira democrática se convertem em elites plutocráticas. Nosso modelo também permite esse tipo de abordagem. A diferenciação é essencialmente temporal, ou seja, num caso a classificação considera a posição social no momento da filiação, no outro, o status social em dado momento da trajetória partidária em comparação com seu ponto inicial.
} 
Inversamente, podemos esperar um maior volume de recrutamentos democráticos paraa-base do que para-a-elite. Mas isso pode variar de partido para partido e de período para período, e deverá ser capturado analiticamente por meio da concentração do foco investigativo. Concentrando-se apenas no recrutamento da elite partidária, será possível distinguir a forma de recrutamento que predomina, mantendo-se o meio constante. Em outros termos, mantendo-se constante o meio de recrutamento, uma vez que o foco é concentrado nos recrutamentos para-a-elite, avaliam-se as formas enquanto variáveis democrática ou plutocrática. O mesmo pode ser aplicado com o foco delimitado ao recrutamento para-a-base. A depender do interesse do analista, pode-se inverter essa lógica, mantendo-se a forma de recrutamento constante para apreender as variações de volume dos meios de recrutamento - para-a-base ou para-a-elite. O Quadro 2 sintetiza as modalidades e meios de recrutamento.

\section{Quadro 2}

Formas e meios de recrutamento partidário

\begin{tabular}{|c|c|c|c|}
\hline & Formas & Meios & Características \\
\hline \multirow{2}{*}{ Quanto ao escopo } & Aberta & $\begin{array}{l}\text { Para a base } \\
\text { Para a elite }\end{array}$ & $\begin{array}{l}\text { Sem parentesco com membros antigos da } \\
\text { elite partidária }\end{array}$ \\
\hline & Fechada & $\begin{array}{l}\text { Para a base } \\
\text { Para a elite }\end{array}$ & $\begin{array}{c}\text { Parentesco próximo com membros da elite } \\
\text { partidária }\end{array}$ \\
\hline \multirow{2}{*}{ Quanto à origem } & Democrática & $\begin{array}{l}\text { Para a base } \\
\text { Para a elite }\end{array}$ & $\begin{array}{l}\text { Classes baixa e média, trabalhadores } \\
\text { manuais e de serviços, profissionais } \\
\text { liberais e micro e pequenos empresários }\end{array}$ \\
\hline & Plutocrática & $\begin{array}{l}\text { Para a base } \\
\text { Para a elite }\end{array}$ & $\begin{array}{c}\text { Classes média-alta e alta, grandes e } \\
\text { médios empresários dos setores produtivo } \\
\text { e financeiro }\end{array}$ \\
\hline
\end{tabular}

Fonte: Elaborado pelos autores.

Analiticamente, é importante saber qual forma de recrutamento é predominante porque, dependendo do escopo e da origem, podemos ter partidos mais oligárquicos ou aristocráticos, mais plutocráticos ou democráticos. Com o predomínio do recrutamento fechado, temos a formação de oligarquias familiares; com a prevalência do recrutamento aberto, temos a formação de aristocracias que correspondem à renovação das elites partidárias independentemente do parentesco, pois baseada nas habilidades necessárias para galgar posições de liderança no interior da organização ${ }^{28}$. Com o predomínio de

\footnotetext{
${ }^{28}$ Aqui fazemos distinção entre aristocracia e oligarquia. Aristocracia corresponde aos mais qualificados para as posições partidárias, com base em atributos pessoais como esforço, talento, tenacidade etc. Tais características e trajetória conduzem às elites aristocráticas. Quando a elite é formada apenas em decorrência dos vínculos familiares, temos a formação de elites oligárquicas. Provavelmente, como nos
} 
UMA TIPOLOGIA DO RECRUTAMENTO PARTIDÁRIO

recrutamentos democráticos, membros do demos poderão ser alçados às posições de liderança, dado que tal trajetória independe da posição social. Obviamente, o dinheiro pode ser determinante nesse percurso, mas, ainda assim, será uma forma de recrutamento que descarta o patrimônio como fator principal para a seleção da elite partidária. Quando predomina o recrutamento plutocrático, as habilidades pessoais não serão condições exclusivas, uma vez que devem estar associadas à riqueza pessoal que garante independência ao indivíduo em relação aos ganhos salariais da política profissional, assim como prestígio e apoio junto à sua classe e, muitas vezes, perante as demais.

Novamente, é plenamente lógico supor que os partidos combinem as formas de recrutamento quanto à origem do recrutado. Dificilmente um partido pode recorrer a apenas uma base social para angariar novos membros. De modo geral, todos os partidos que tentarem estruturar alguma base organizacional com alguma militância ou membros ocasionais terão que estar abertos ao recrutamento democrático. Por isso, o procedimento mais indicado para diferenciar a forma de recrutamento quanto à origem do recrutado é focar a análise no grupo dirigente e nas bancadas parlamentares e executivas dos partidos. O perfil socioeconômico dos membros selecionados para cargos de direção ou para a disputa de cargos eletivos, com sua eventual ocupação, mostrará a forma de recrutamento quanto à origem mais relevante que predomina em cada partido. Similarmente, quando houver recrutamento intensivo para-a-elite, o mesmo tipo de análise proporcionará distinção equivalente; ou seja, tanto membros já antigos do partido como novos filiados recrutados pelo tipo intensivo podem ter seu perfil socioeconômico analisado para seu enquadramento na forma de recrutamento adotada quanto à origem, se plutocrática ou democrática. Finalmente, tanto os recrutamentos democráticos como os recrutamentos plutocráticos podem ser abertos ou fechados.

\section{Modalidades e submodalidades de recrutamento}

Há duas modalidades de recrutamento que chamamos de captação e recepção. Essas modalidades correspondem às motivações dos partidos e dos indivíduos para a filiação. Quando ocorre a filiação por captação, há uma política proativa do partido, que atua de maneira deliberada na busca de novos membros, com ou sem experiência prévia. Nesse caso, os partidos podem atraí-los por intermédio de duas submodalidades de filiação: cooptação ou conviç̧ão. Quando o membro é atraído por algum interesse conjuntural, visando algum benefício circunstancial associado ao partido, como o oferecimento de vaga para candidatura a algum cargo eletivo, temos um processo de captação-por-cooptação. Se a atração envolver algum tipo de convergência com os objetivos, as metas, o programa ou a ideologia do partido, ocorrerá um processo de captação-por-conviç̧ão. Quando isso suceder, um membro potencial do partido será

outros casos, essas duas formações se manifestam simultaneamente em diversos partidos, o que significa que o importante da análise é detectar qual formação é a predominante. 
PAULO PERES; AMANDA MACHADO

convencido de que somente como um quadro dessa legenda será capaz de assegurar a defesa de certos valores e determinadas políticas.

Para os casos em que o partido simplesmente recebe novos membros como resultado da iniciativa deles próprios, ou seja, a organização tem uma atuação reativa, temos a filiação-por-recepção. Esta também contempla duas submodalidades de ocorrência: adesão ou identificação. No primeiro caso, recepção-por-adesão, o novo membro toma a iniciativa de filiar-se ao partido em decorrência de algum interesse conjuntural e pragmático, como ter uma legenda que facilite sua candidatura em determinada eleição, por exemplo. Quando os novos membros filiam-se espontaneamente ao partido porque se identificam com ele, suas lideranças, seu programa, suas políticas, temos então uma recepção-por-identificação. Portanto, no que se refere às motivações do partido, as filiações podem ocorrer por captação, e quanto às motivações dos recém-filiados, esse processo pode ocorrer por recepção. Isso significa que o partido e os filiados são tomados como parâmetro principal para a análise das motivações que conduzem às filiações. O Quadro 3 resume as modalidades e submodalidades de recrutamento.

Quadro 3

Modalidades e submodalidades de recrutamento

\begin{tabular}{|c|c|c|}
\hline Modalidades & Submodalidades & Motivações \\
\hline Captação & Cooptação & Interesses pragmáticos \\
\hline $\begin{array}{c}\text { (Atuação proativa do partido) } \\
\text { (Atuação reativa do filiado) }\end{array}$ & Convicção & Interesses programáticos \\
\cline { 2 - 3 } Recepção & Adesão & Interesses pragmáticos \\
\hline $\begin{array}{c}\text { (Atuação reativa do partido) } \\
\text { (Atuação proativa do filiado) }\end{array}$ & Identificação & Interesses programáticos \\
\cline { 2 - 3 }
\end{tabular}

Fonte: Elaborado pelos autores.

Como pode ser percebido, as filiações por meio da cooptação e da adesão geralmente têm como motivação interesses meramente circunstanciais e pragmáticos, sejam dos partidos ou dos novos filiados. Já as filiações por convicção e por identificação, ao contrário, são motivadas por interesses mais duradouros e programáticos, relacionados a alguma semelhança com a visão de mundo dos novos filiados e dos respectivos partidos. Do ponto de vista da organização partidária, um comportamento proativo na busca de novos membros pode resultar na difusão de sua doutrina e, com isso, na captura de filiados que se identificam com sua visão de mundo - uma captaçãopor-convicção. Mas o partido também pode ser proativo na busca de membros cuja filiação será pragmática, de acordo com interesses circunstanciais comuns - uma captação-por-cooptação. No caso de ser meramente reativo, o partido pode receber filiados com base nas mesmas características, ou seja, por adesão (relação pragmática) ou identificação (relação programática). 
UMA TIPOLOGIA DO RECRUTAMENTO PARTIDÁRIO

Com base nessa classificação é possível distinguir aspectos importantes das filiações. Podemos, por exemplo, diferenciar aquelas que são baseadas em interesses estritamente pragmáticos daquelas alicerçadas em motivações de caráter mais programático. Podemos discernir os partidos que investem na busca de novos filiados daqueles que apenas recebem filiados que os procuram. O mesmo pode ser diferenciado em relação aos filiados, já que podemos identificar aqueles que procuram os partidos por interesses meramente circunstanciais e aqueles que o fazem em decorrência da identificação com seus programas e ideologias.

A combinação das modalidades de recrutamento é igualmente uma estratégia partidária que pode ser antecipada. Os partidos podem recrutar membros visando aos interesses pragmáticos da organização e, ao mesmo tempo, fazendo apelos aos interesses também pragmáticos dos novos filiados. Podem, ainda, combinar tal curso de ação com um recrutamento que visa aos interesses ideológicos convergentes da organização e dos recém-filiados. Portanto, podem-se combinar interesses ideológicos e pragmáticos seja do partido, seja do recrutado, com gradações diversas. Recrutamentos pragmáticos podem combinar cooptação e adesão, assim como recrutamentos programáticos podem combinar convicção e identificação. Isso quer dizer que o partido pode ser pragmático/programático e ativo/reativo em graus variados, conforme a circunstância e o contexto ambiental. O importante, na análise, é detectar essas variações e as consequências disso para seu desempenho e sua evolução adaptativa.

\section{Síntese da classificação}

No Quadro 4, sintetizamos a classificação do recrutamento partidário - seus tipos e subtipos, formas, meios, modalidades e submodalidades. Como se vê, tanto o recrutamento intensivo como o recrutamento extensivo podem ser abertos ou fechados, plutocráticos ou democráticos, por captação ou por recepção. As exclusividades ficam por conta apenas das modalidades de recrutamento. As filiações por captação ocorrem somente por cooptação ou convicção; as filiações por recepção ocorrem apenas por adesão ou identificação. Como o recrutamento extensivo é o tipo que demanda maior investimento, pois visa à formação política dos filiados, é de esperar que o partido assuma um comportamento proativo, recorrendo à filiação-por-captação, embora não se possa descartar algum grau de filiação-por-recepção. Nos casos de recrutamento extensivo, as modalidades mais comuns de filiação são por convicção e por identificação. Inversamente, partidos que investem no recrutamento intensivo para renovar suas lideranças geralmente atraem novos filiados por cooptação ou adesão, uma vez que o que se busca é alguém já formado politicamente ou com elevada popularidade para selecioná-lo como candidato a algum cargo eletivo. Mesmo no caso de haver a simples filiação, sem a pretensão de lançamento de candidatura ou recomposição de lideranças, os meios de atração serão os mesmos, com a diferença de que nem experiência política prévia nem popularidade serão características determinantes para a entrada no partido. 
PAULO PERES; AMANDA MACHADO

De fato, os partidos podem sair à cata de filiações de indivíduos sem qualquer formação política prévia ou com experiência de militância anterior bastante reduzida e precária com o intuito de apenas aumentar o número de filiados, ou então para aumentar o número de candidatos a algum cargo parlamentar com a intenção de elevar o número total de votos da legenda. Em sistemas eleitorais como o brasileiro, com a distribuição das cadeiras legislativas de acordo com os quocientes eleitoral e partidário e um número elevado de candidaturas, os recrutamentos por cooptação e adesão podem ser estratégicos para a conquista de vagas no parlamento. O recrutamento-por-cooptação pode ser igualmente estratégico quando o partido possui algum grau de facciosismo interno e toma decisões importantes por mecanismos que envolvem toda a sua base de membros - as facções podem cooptar novos filiados para aumentar seu peso nas decisões intrapartidárias. Sendo assim, dificilmente esses novos membros serão filiados com o propósito de ocupar algum cargo de direção na organização.

Quadro 4

Síntese do modelo tipológico de recrutamento partidário

\begin{tabular}{|c|c|c|c|c|c|}
\hline Tipos & Subtipos & Formas & Meios & Modalidades & Submodalidades \\
\hline Extensivo & Para a base & Aberta/ & $\begin{array}{c}\text { Para a } \\
\text { base } \\
\text { Pechada } \\
\text { Para a militância }\end{array}$ & Captação & Cooptação \\
\hline Intensivo & Para candidaturas/bancada & $\begin{array}{c}\text { Para a } \\
\text { base } \\
\text { Demõo } \\
\text { Plutocrática/ } \\
\text { Para a } \\
\text { elite }\end{array}$ & Recepção & Adesão \\
\hline
\end{tabular}

Fonte: Elaborado pelos autores.

Com relação à experiência prévia de participação em outras organizações, incluindo-se os partidos concorrentes, é de esperar que as filiações por cooptação, adesão e convicção ocorram com indivíduos que já possuem alguma trajetória e formação política. Nesse caso, tais filiações corresponderão às formas de recrutamento intensivo. Os recrutamentos extensivos, por seu turno, deverão corresponder às filiações por identificação, atingindo indivíduos sem experiência política prévia de participação em alguma organização política. Em qualquer um dos casos, o recrutamento pode ser aberto ou fechado, democrático ou plutocrático. Presumivelmente, o recrutamento de jovens pode ser do tipo extensivo-por-identificação ou do tipo intensivo-por-convicção, tanto abertos como fechados. No caso dos recrutamentos fechados, ou seja, quando a "circulação das elites" se processa de forma endógena às famílias com alguma tradição ou trajetória política, é mais provável que estes, no caso dos jovens, sejam extensivospor-identificação. Obviamente, indivíduos adultos que pertençam a alguma família tradicional ou "clã" político podem continuar a ser recrutados pelos partidos, 
UMA TIPOLOGIA DO RECRUTAMENTO PARTIDÁRIO

especialmente os concorrentes daqueles aos quais esses indivíduos são filiados; mas essa atração ocorrerá por recrutamento intensivo (por cooptação, adesão ou convicção) de políticos com alguma experiência prévia e que dispensam a etapa de formação/treinamento. Com os jovens, esse tipo de recrutamento também pode ocorrer, mas em menor escala.

De modo geral, o mais importante é identificar os partidos que investem na formação e diferenciá-los daqueles que descartam essa etapa. Obviamente, em termos estratégicos, é de esperar que os partidos invistam nos dois tipos de recrutamento, o extensivo e o intensivo. Um desequilíbrio muito acentuado em favor do recrutamento intensivo pode ser um problema reprodutivo no longo prazo, pois significaria um baixo investimento em formação político-partidária. Mesmo os partidos que investem mais no recrutamento extensivo podem enfrentar problemas semelhantes, caso essa formação seja pouco efetiva ou diversos desses militantes não encontrem espaço para ocupar posições de importância na organização ou fora dela. Num partido com predomínio do recrutamento intensivo e fechado, seja plutocrático ou democrático, as chances de um membro da base partidária chegar a alguma posição de direção ou ser selecionado para disputar eleições para cargos executivos serão muito reduzidas.

Outro ponto relevante deve ser ressaltado: é possível que fiquemos tentados a procurar associações entre os tipos partidários estabelecidos pela literatura especializada e os tipos de recrutamentos propostos no modelo que acabamos de apresentar. Reconhecemos que o hábito de procurar tipos partidários ou analisar os partidos pelo esquadro dos tipos partidários é bastante arraigado, constituindo uma visão de mundo adquirida na própria formação baseada no estudo das teorias e análises comparadas sobre o tema. Certamente, seu abandono por completo provoca resistências. Por isso é forçoso observar que, na nossa perspectiva, a aplicação dessa tipologia não impede que os pesquisadores, caso ainda julguem necessário, explorem as possíveis relações entre o perfil de recrutamento e os tipos partidários canônicos.

Com efeito, se vasculharmos a literatura especializada na taxonomia das organizações partidárias, encontraremos indícios de que o recrutamento intensivo está associado aos partidos de quadros, catch-all, profissional-eleitoral e cartel. Em determinada medida, possivelmente variada, cada um desses tipos partidários investiu em alguma combinação das orientações subtípicas do recrutamento intensivo. O partido de quadros (Duverger, 1951) promovia um recrutamento fechado não apenas ao contexto parlamentar, mas também em relação à estrutura social, dedicando-se a recrutar membros da aristocracia diretamente para as atividades legislativas e eleitorais, sem qualquer preocupação com sua formação interna, até porque sequer havia uma organização partidária no sentido moderno do termo. O partido catch-all (Kirchheimer, 1966), assim como o profissional-eleitoral (Panebianco, 1982) - que nada mais é do que uma caracterização mais detalhada da estrutura organizacional do partido catch-all -, inovou ao promover um recrutamento mais aberto, e talvez muito indiscriminadamente aberto para o gosto de Kirchheimer, mas dispensou igualmente o processo de formação 
PAULO PERES; AMANDA MACHADO

política de seus quadros e ainda manteve a orientação eleitoral do seu recrutamento intensivo. O partido cartel conservou o recrutamento aberto e intensivo do partido catchall, assim como a orientação eleitoral, inovando no aumento do investimento no recrutamento intensivo direcionado à militância profissional de uma burocracia crescente e capaz de dar suporte a sua meta de captura do Estado, mediante a tática da "ocupação de território".

No âmbito da taxonomia canônica, o único que desvia desse padrão de modalidade de recrutamento é o partido de massas (Duverger, 1951). Este tinha como estratégia exclusiva o recrutamento extensivo. Todos os outros tipos tendem a dar maior ênfase no recrutamento intensivo, o que mostra que os partidos de massas não correspondem à etapa final da "evolução partidária", conforme se pode depreender das entrelinhas de parte importante da literatura especializada. Na verdade, podemos até dizer que o partido de massas constitui antes uma exceção na fauna partidária do que propriamente uma regra ou uma etapa final e necessária da evolução desse tipo de organização. Ao contrário, o que se convencionou chamar de partido de massas correspondeu a uma modalidade organizacional de um contexto ambiental específico. A evolução do ambiente político de cada contexto deu ensejo ao retorno do recrutamento intensivo e à ênfase em alguns de seus subtipos, com combinações variadas.

Sendo rigorosos, entretanto, perceberemos que essa associação não vai além de alguns elementos epidérmicos e, por isso, ainda sustentamos, conforme já mencionado anteriormente, que não nos parece producente recorrer aos tipos partidários consagrados na literatura comparada para estudar o perfil de recrutamento. Se olharmos mais atentamente para o fenômeno, perceberemos que aquilo que, em princípio, separa os dois grupos de tipos partidários canônicos, pelo menos no que se refere ao tipo de recrutamento, é o predomínio de um ou de outro - enquanto os partidos de massas preferem o recrutamento extensivo, os demais preferem o recrutamento intensivo. Porém, as combinações dos tipos e subtipos de recrutamento podem variar de tal maneira no tempo, no espaço, em graus e modos, que fica difícil distinguir um tipo partidário em função dessa característica. Desde que nível de recrutamento intensivo um partido de massas, que deve privilegiar o recrutamento extensivo, deixará de ser um partido de massas? Mesmo que seja possível estabelecer esse nível e mensurá-lo de forma segura, esse partido passará a ser de que tipo? Cartel? Profissional-eleitoral? Catch-all? Partido de quadros? Novo partido de quadros? De fato, no que se refere ao recrutamento, quando um partido atravessa o "Rubicão" rumo a um "tipo" diferente do tradicional partido de massas, ele entra numa área cinzenta da taxonomia convencional. Mesmo que seja possível identificar que "tipo" de partido está em cena com base em outras variáveis, do ponto de vista do recrutamento partidário as combinações estratégicas dos tipos e subtipos de recrutamento transitam entre os partidos de maneira intercambiável.

Em razão disso, julgamos mais producente analisar os tipos de recrutamento como respostas adaptativas ao ambiente, as quais podem provocar efeitos sobre o 
UMA TIPOLOGIA DO RECRUTAMENTO PARTIDÁRIO

desempenho do partido e sua organização. Por sua vez, a adoção das combinações dos tipos, subtipos, meios, formas, modalidades e submodalidades de recrutamento será condicionada pelos ambientes externo e interno dos partidos. Isso significa que o estudo dos tipos de recrutamento deve, primeiramente, catalogar aqueles que são predominantes e, depois, analisá-los como reações adaptativas ao ambiente externo e condicionadas pelo ambiente interno. Uma terceira etapa de um estudo com esse enquadramento deve considerar se tais estratégias foram bem-sucedidas, bem como seus efeitos sobre o ambiente político externo e a estrutura organizacional do partido ${ }^{29}$.

\section{Conclusão}

Essencialmente, nosso maior objetivo neste artigo foi tentar trazer uma pequena contribuição metodológica para a área de estudos sobre recrutamento partidário. Consideramos que nossa proposta traz três contribuições. A primeira é chamar a atenção para o fato de que os estudos sobre recrutamento partidário são muito restritos, pois identificam recrutamento com seleção de candidatos. Procuramos mostrar que o recrutamento partidário pode abranger três processos e a seleção de lideranças corresponde a apenas um deles. A segunda contribuição foi apresentar uma definição mais abrangente do conceito e do fenômeno do recrutamento partidário. Enfatizamos que ele pode ser dividido em três etapas separáveis e não necessariamente sequenciais: a filiação, a formação e a seleção do quadro partidário para algum cargo relevante, interna ou externamente. Em decorrência disso, a filiação também não pode ser tomada como sinônimo de recrutamento, mas apenas como uma de suas etapas, o que abre espaço para o estudo das etapas iniciais e intermediárias do recrutamento, em complementação à ampla agenda de pesquisas já desenvolvida na literatura especializada compreendendo sua etapa final. A terceira contribuição foi a proposição de uma tipologia para o estudo do recrutamento partidário, inclusive de sua fundamentação epistemológica.

Em termos teóricos e metodológicos, consideramos que nosso modelo heurístico permite não apenas o enquadramento do fenômeno do recrutamento, mas também a consideração das estratégias partidárias nesse sentido enquanto respostas adaptativas ao ambiente político, assim como as consequências de cada estratégia para a organização partidária. Ele permite, também, abordar o fenômeno de diversos modos e com variados recortes - é possível, por exemplo, analisar o recrutamento partidário nas instâncias municipal, estadual e nacional, em conjunto ou separadamente. É possível, ainda, analisar o recrutamento tomando-se como universo os filiados comuns da base

\footnotetext{
${ }^{29}$ Uma possível questão de investigação a partir disso é saber se haveria efeitos negativos de longo prazo para os partidos que se restringirem exclusivamente à atração de lideranças já formadas em outras instituições ou de outsiders para renovar seus quadros e promover a "circulação de sua elite". Ou então, se, pelo contrário, a depender do ambiente no qual se inserem, o recrutamento intensivo e alguma de suas variantes podem ser positivos no que se refere à sobrevivência da organização e ao aumento do seu poder eleitoral e governamental.
} 
partidária, os membros da direção e das bancadas legislativas e os titulares dos cargos executivos, também de forma isolada ou em conjunto, seja como estudo de caso ou com perspectiva comparada.

Por último, esperamos que análises que por ventura recorreram a esse modelo dedutivo possam promover "retornos indutivos", ou seja, que seus dados possam servir de parâmetros para ajustes no esquema classificatório. Afinal, como já observado, tratase de uma tipologia provisória e sujeita a alterações e aperfeiçoamentos. Portanto, a conjectura que levou à tipologia está aberta a refutações empíricas ou lógicas que servirão para ajustes nas categorias propostas. Essencialmente, esperamos que possa se formar uma agenda de pesquisas voltada ao estudo dos processos de filiação e formação de quadros partidários, de modo a termos a complementaridade necessária nos conhecimentos já produzidos sobre a seleção de candidatos e a carreira política.

Paulo Peres - Universidade Federal do Rio Grande do Sul (UFRGS), Instituto de Filosofia e Ciências Humanas (IFCH), Departamento e Programa de Pós-Graduação em Ciência Política (PPG-CP UFRGS). E-mail:<peres.ps@gmail.com>.

Amanda Machado - Universidade Federal do Rio Grande do Sul (UFRGS), Instituto de Filosofia e Ciências Humanas (IFCH), doutora pelo Programa de Pós-Graduação em Ciência Política na UFPR. E-mail: <sm.amandinha@gmail.com>.

\section{Referências bibliográficas}

ALDRICH, J. Why parties? The origin and transformation of political parties in America. Chicago: Chicago University Press, 1995.

BAILEY, K. "Polythetic reduction of monothetic property space". In: Costner, H. (ed.). Sociological Methodology, vol. 1. San Diego: Jossey-Bass, 1972.

. "Monothetic and polythetic typologies and their relation to conceptualization

measurement, and scaling". American Sociological Review, vol. 38, p. 18-32, 1973.

Clusters analysis. In: HeISE, D. (ed.). Sociological Methodology, vol. 2. San Diego: Jossey-Bass, 1974.

. Typologies. In: BorgattA, E.; Borgatta, M. (eds.). Encyclopedia of sociology. New York: MacMillan, 1992.

\section{4.}

Typologies and taxonomies: an introduction to classification techniques. London: Sage,

BARBER, J. The lawmakers: recruitment and adaptation to legislation. New Haven: Yale University Press, 1965.

BLACK, G. "A theory of political ambition: careers choice and the role of structural incentives". American Political Science Review, vol. 66, no 1, p. 144-159, 1972.

BLYTh, M.; KATZ, R. "From catch-all politics to cartelisation". West European Politics, vol. 28, no 1, p. 33-60, 2005. 
Bolognesi, B. "A seleção de candidaturas no DEM, PMDB, PSDB e PT nas eleições legislativas federais brasileiras de 2010: percepções dos candidatos sobre a formação das listas". Revista de Sociologia e Política, vol. 21, no 46, p. 45-68, 2013.

Bolognesi, B.; Medeiros, P. "Aspectos motivacionais do recrutamento político: um estudo inicial dos candidatos a deputado federal no Brasil [2010]". Paraná Eleitoral: Revista Brasileira de Direito Eleitoral e Ciência Política, vol. 3, no 2, p. 301-326, 2014.

BOWKER, G.; STAR, S. Sorting things out: classification and its consequences. Cambridge: Cambridge University Press, 1999.

BragA, M. S.; AMARAL, O. "Implicações do processo de seleção de candidatos na competição partidária: o caso brasileiro". Revista de Sociologia e Política, vol. 21, no 46, p. 33-43, 2013.

BRAGA, M. S.; Bolognesi, B. Dimensões do processo de seleção da classe política brasileira: autopercepções dos candidatos à Câmara dos Deputados nas eleições de 2010. In: MARENCO, A. (org.). Os eleitos: representação e carreiras políticas em democracias. Porto Alegre: Editora da UFRGS, 2013.

Braga, M. S.; VeigA, L.; Miríade, A. "Recrutamento e perfil dos candidatos e dos eleitos à Câmara dos Deputados nas eleições de 2006". Revista Brasileira de Ciências Sociais, vol. 24, no 70, p. 123142, 2009.

BRUTER, M.; HARRISON, S. The future of our democracies: young party members in Europe. London: Palgrave Macmillan, 2009.

CAMP, R. Political recruitment across two centuries: Mexico 1884-1991. Austin: University of Texas Press, 1995.

. Political recruitment, governance and leadership: has democracy made a difference?. In: Siavelis, P.; Morgenstern, S. (eds.). Pathways to power: political recruitment and candidate selection in Latin America. Pennsylvania: Pennsylvania State University Press, 2008.

ClaRke, A.; PRIMO, D. "Modernizing political science: a model-based approach". Perspectives on Politics, vol. 5, no 4, p. 741-753, 2007.

. A model discipline: political science and the logic of representations. Oxford: Oxford University Press, 2012.

CHANDRA, C. "Supply chain system taxonomy: a framework and methodology". Human Systems Management, vol. 24, no 4, p. 245-258, 2005.

CodAto, A.; CostA, L. D.; MAssimo, L. (orgs.). Retratos da classe política brasileira: estudos de ciência política. Curitiba: Novas Edições Acadêmicas, 2015.

Collier, D.; LAPORTE, J.; SeAwright, J. "Putting typologies to work: concept formation, measurement, and analytic rigor". Political Research Quarterly, vol. 65, no 1, p. 217-232, 2012.

CostA, L. D.; CODATO, A. A profissionalização da classe política brasileira: um perfil dos senadores da República. In: MARENCO, A. (org.). Os eleitos: representação e carreiras políticas em democracias. Porto Alegre: Editora da UFRGS, 2013.

COSTA, P. R.; COSTA, L. D.; NUNES, W. "Os senadores-empresários: recrutamento, carreira e partidos políticos dos empresários no Senado brasileiro (1986-2010)". Revista Brasileira de Ciência Política, vol. 14, no 2, p. 227-253, 2014.

CORADINI, O. Em nome de quem? Recursos sociais no recrutamento da elite política. Rio de Janeiro: Relume-Dumará, 2001. 
CORADINI, O. "Engajamento associativo-sindical e recrutamento de elites políticas: tendências recentes no Brasil". Revista de Sociologia Política, n²8, p. 181-203, 2007.

CROSS, W. Party leadership selection and intra-party democracy. In: CROSS, W.; KATZ, R. (eds.). The challenges of intra-party democracy. Oxford: Oxford University Press, 2013.

CZUdnowski, M. Political recruitment. In: Greenstein, F.; Polsby, N. (eds.). Handbook of political science: micropolitical theory. Massachusetts: Addison-Wesley, 1975.

DALTON, R. Citizen politics. Washington: Congressional Quarterly Press, 2005.

DALTON, R.; WATtenBerg, M. Parties without partisans: political change in advanced industrial societies. Oxford: Oxford University Press, 2002.

Delwit, P. Still in decline? Party membership in Europe. In: VAN HAUTE, E. (ed.). Party membership in Europe: exploration into the anthills of party politics. Bruxelles: Université de Bruxeles, 2011.

Diamond, L.; Gunther, R. (eds.). Political parties and democracy. Baltimore: Johns Hopkins University Press, 2001.

DIESING, P. Patterns of discovery in the social sciences. New Brunswick: Aldine Transactions, 1971.

DoTY, D.; GLICK, W. "Typologies as a unique form of theory building: towards improved understanding and modelling". Academy of Management Review, vol. 19, n 2, p. 230-251, 1994.

DUVERGER, M. Les partis politique. Paris: Armand Colin, 1951.

EPSTEIN, L. Political parties in Western democracies. New Jersey: Transaction, 1980.

EULAU, H.; CZUDNOWSKI, M. Elite recruitment in democratic polities. New York: John Wiley and Sons, 1976.

FLEISCHER, D. "O pluripartidarismo no Brasil: dimensões socioeconômicas e regionais do recrutamento legislativo (1946-1967)". Revista de Ciência Política, vol. 24, no 1, p. 49-75, 1981.

Fowler, L. Candidates, Congress, and the American democracy. Ann Arbor: University of Michigan Press, 1993.

Fowler, L.; McLure, R. Political ambition: who decides to run for Congress. New Haven: Yale University Press, 1990.

FREY, F. The Turkish political elite. Cambridge: M.I.T. Press, 1966.

Gallagher, M.; MARSh, M. Candidate selection in comparative perspective. London: Sage, 1988.

GAUJA, A. The politics of party policy: from members to legislators. Houndmills: Palgrave MacMillan, 2013.

GoSNELL, H. Negro politicians: the rise of negro politics in Chicago. University of Chicago Press, 1933.

. Machine politics: Chicago model. Chicago: University of Chicago Press, 1937.

GUNTHER, R.; DiAmond, L. Types and functions of parties. In: GUNTHER, R.; DiAmOND, L. (eds.).

Political parties and democracy. Baltimore: Johns Hopkins University Press, 2001.

Gunther, R.; Montero, J.; Linz, J. Political parties: old concepts and new challenges. Oxford: Oxford 
UMA TIPOLOGIA DO RECRUTAMENTO PARTIDÁRIO

University Press, 2002.

GREGORY, S. "The nature of theory in information systems". MIS Quarterly, vol. 30, no 3, p. 611-642, 2006.

Hazan, R. Candidate selection. In: Leduc. L.; Niemi, R.; Norris, P. (eds.). Comparing democracies. Thousand Oaks: Sage, 2002.

Hempel, C. "Typological methods in the natural and social sciences". Proceedings of American Philosophical Society, vol. 1, p. 656-686, 1952.

. Explanation in science and history. In: ColodNy, R. (ed.). Frontiers of science and philosophy. Pittsburgh: University of Pittsburgh Press, 1962.

Hempel, C.; Oppenheim, P. "Studies in the logic of explanation". Philosophy of Science, vol. 15, p. 567-579, 1948.

JACOB, E. "Classification and categorization: a difference that makes a difference". Library Trends, vol. 52, no 3, p. 515-540, 2004.

KATZ, R. "The problem of candidate selection and models of party democracy". Party Politics, vol. 7, no 3, p. 277-296, 2001.

KATZ, R., et al. "The membership of political parties in European democracies (1960-1990)". European Journal of Political Research, vol. 22, no 3, p. 329-345, 1992.

KATZ, R.; MAIR, P. Party organizations: a data handbook on party organizations in Western democracies (1960-1990). London: Sage, 1992.

. "The evolution of party organizations in Europe: the three faces of party organization". American Review of Politics, vol. 14, p. 593-617, 1993.

" "Changing models of party organization and party democracy: the emergence of the cartel party". Party Politics, vol. 1, no 1, p. 5-28, 1995.

. "Cadre, catch-all, or cartel? A rejoinder". Party Politics, vol. 2, no 4, p. 524-534, 1996.

. The ascendancy of the party in public office: party organizational change in twentiethcentury democracies. In: GunTHer, R.; MONTERo, J.; Linz, J. (eds.). Political parties: old concepts and new challenges. Oxford: Oxford University Press, 2002.

2009.

. "The cartel party thesis: a restatement". Perspectives on Politics, vol. 7, no 4, p. 753-766, $111,2012$.

"Parties, interest groups and cartels: a comment". Party Politics, vol. 18, n$^{0} 1$, p. 107-

KIRCHHEIMER, O. "The waning of opposition in parliamentary regimes". Social Research, vol. 24, p. 127-156, 1957.

. "The transformation of the Western European party system". In: LAPALOMBARA, J.; WeineR, M. (eds.). Political parties and political development. Princeton: Princeton University Press, 1966.

KIRCHHEIMER, O. "A transformação dos sistemas partidários na Europa Ocidental". Revista Brasileira de Ciência Política, vol. 7, no 1, p. 349-388, 2012.

KITSCHELT, H. "Citizen, politicians, and party cartelization". European Journal of Political Research, vol. 37, no 2, p. 149-179, 2000. 
KLUGE, S. "Empirically grounded construction of types and typologies in qualitative social research". Qualitative Social Research, vol. 1, nº 1, p. 1-8, 2000.

KöLLN, A. K. "Party membership in Europe: testing party-level explanations of decline". Party Politics, vol. 22, no 4, p. 1-13, 2016.

KOoLE, R. "Cadre, catch-all or cartel? A comment on the notion of the cartel party". Party Politics, vol. 2, no 4, p. 507-534, 1996.

KOPECKY, P. "Developing party organizations in East-Central Europe: what type of party is likely to emerge?". Party Politics, vol. 1, no 4, p. 515-534, 1995.

KROUWEL, A. "Otto Kirchheimer and the catch-all party". West European Politics, vol. 26, no 2, p. 2340, 2003.

2006.

Party models. In: KATZ, R.; CROTTY, W. (eds.). Handbook of party politics. London: Sage, Press, 2012.

Party transformations in European democracies. New York: State University of New York

KUHN, T. The structure of scientific revolutions. Chicago: The University of Chicago Press, 1962.

LaVe, C.; March, J. An introduction to models in the social sciences. New York: Harper and Row, 1975.

LAWSON, K. Political parties and linkage: a comparative perspective. New Haven: Yale University Press, 1980.

LAZARSFELD, P. "Some remarks on the typological procedures in social research". Zeitschrift für Sozialforschung, vol. 6, p. 119-139, 1937.

LAZARSFELD, P.; BARTON, A. Qualitative measurement in the social sciences: classification, typologies, and indices. In: LERNER, D.; LASSWELL, H. (eds.). The policy sciences. Stanford: Stanford University Press, 1951.

LeISERSON, A. Parties and politics: an institutional and behavioral approach. New York: Knopf, 1958.

LEWIS, P. G. Political parties in post-communist Eastern Europe. London: Routledge, 2000.

LOMNICKI, A. "Individual-based models and the individual-based approach to population ecology". Ecology Modeling, vol. 115, p. 191-198, 1999.

Love, J. A locomotiva: São Paulo na federação brasileira (1890-1937). Rio de Janeiro: Paz e Terra, 1982.

LOVE, J.; BARICKMAN, B. Regional elites. In: Conniff, M.; MCCANN, F. (eds.). Modern Brazil: elites and masses in historical perspective. Nebraska: University of Nebraska Press, 1991.

Loewenberg, G.; PATterson, S. Comparing legislatures. Boston: Little, Brown and Co., 1979.

MAINWARING, S. Rethinking party systems in the third wave of democratization: the case of Brazil. Stanford: Stanford University Press, 1999.

MaInWARING, S.; SCULly, T. Building democratic institutions: party systems in Latin America. Stanford: Stanford University Press, 1995. 
UMA TIPOLOGIA DO RECRUTAMENTO PARTIDÁRIO

MAIR, P. Party system change: approaches and interpretations. Oxford: Oxford University Press, 1997.

MAIR, P. "Democracy beyond parties", eScholarship Respository, Paper 05'06, Center for the Study of Democracy, University of California, Irvine. Disponível em: <http://repositories.cdlib.org/csd/0506>. Acesso em: 12 out. 2005.

$\overline{51,2006 .}$

"Ruling the void: the hollowing of Western democracy". New Left Review, vol. 42, p. 25-

Mair, P.; VAn Biezen, I. V. "Party membership in twenty European democracies (1980-2000)". Party Politics, vol. 7, no 1, p. 5-21, 2001.

MAREnCo, A. "Nas fronteiras do campo político: raposas e outsiders no Congresso Nacional". Revista Brasileira de Ciência Sociais, vol. 12, no 33, p. 87-101, 1997.

. "Le renouveau politique: carrières politiques et liens de parti au Brésil (1946-2002)". Politique et Societés, vol. 23, no 2, p. 109-133, 2002.

. "Still a traditional political class? Patterns of parliamentary recruitment in Brazil". Canadian Journal of Latin American and Caribbean Studies, vol. 30, no 60, p. 13-40, 2005.

. O que podemos explicar estudando carreiras políticas?. In: MARENCO, A. (org.). Os eleitos: representação e carreiras políticas em democracias. Porto Alegre: Editora da UFRGS, 2013.

Marenco, A.; Serna, M. "Por que carreiras políticas na esquerda e na direita não são iguais? Recrutamento legislativo em Brasil, Chile e Uruguai". Revista Brasileira de Ciências Sociais, vol. 22, no 64, p. 93-113, 2007.

MARRADI, A. "Classification, typology, taxonomy". Quality and Quantity, vol. 24, no 2, p. 129-157, 1990.

MARTZ, J. "Political parties and candidate selection in Venezuela and Colombia". Political Science Quarterly, vol. 114, no 4, p. 639-659, 1999.

MARVICK, D. Political and careers. In: SillS, D. (ed.). International encyclopedia of the social sciences. New York: MacMillam, 1968.

MATTHEWS, D. Legislative recruitment and legislative careers. In: LOEWENBERG, G.; PATTERSON, S.; JeWELL, M. (eds.). Handbook of legislative research. Cambridge: Harvard Univesity Press, 1985.

MAY, J. "Opinion structure of political parties: the special law of curvilinear disparity". Political Studies, vol. 21, no 1, p. 135-151, 1973.

MCCLELLAND, D. The achieving society. Princeton: Van Nostrand, 1961.

MCKInNEY, J. Constructive typology and social theory. New York: Meridth Publishing Company, 1966.

MEYER, R. Mapping the mind of the strategist: a quantitative methodology for measuring the strategic beliefs of executives. Erasmus University Press, 2007.

MEZEY, M. Comparative legislatures. Durham: Duke University Press, 1979.

MiCELI, S. Carne e osso da elite política brasileira pós-1930. In: FAusto, B. (org.). História geral da civilização brasileira. Tomo III - O Brasil republicano, sociedade e política (1930-1964). Rio de Janeiro: Difel, 1996.

MiChels, R. Para uma sociologia dos partidos políticos na democracia moderna. Lisboa: Antígona, 2001 [1911]. 
MiLBRATH, L. The Washington lobbyists. Chicago: Rand McNally, 1963.

Moran, E. Human adaptability. Philadelphia: Westview Press, 2008.

Morlino, L. Democracy between consolidation and crisis: parties, groups and citizens in Southern Europe. Oxford: Oxford University Press, 1998.

MüLleR, G. "Comissões e partidos políticos na Câmara dos Deputados: um estudo sobre os padrões partidários de recrutamento para as comissões permanentes". Dados, vol. 48, n 1, p. 371-394, 2005.

NeIVA, P.; IZUMI, M. "Os 'doutores' da federação: formação acadêmica dos senadores brasileiros e variáveis associadas". Revista de Sociologia e Política, vol. 21, no 41, p. 171-192, 2012.

Nowotny, H. "The uses of typological procedures in qualitative macro-sociological studies". Quality and Quantity, vol. 24, no 1, p. 3-37, 1971.

NORRIS, P. Legislative recruitment. In: LedUC, N.; NORRIS, P. (eds.). Comparing democracies: elections and voting in global perspective. London: Sage, 1996.

. Introduction: theories of recruitment. In: NoRRIS, P. (ed.). Passages to power: legislative recruitment in advanced democracies. New York: Cambridge University Press, 1997.

Reinventing political activism. Cambridge: Cambridge University Press, 2000.

2006.

. Recruitment. In: KATZ, R.; CROTTY, W. (eds.). Handbook on political parties. London: Sage,

NoRRIS, P., et al. "Party selectorates in Australia, Britain and Canada: prolegomena for research in the 1990s". The Journal of Commonwealth and Comparative Politics, vol. 28, p. 219-245, 1990.

NoRRIS, P.; Lovenduski, J. Political recruitment: gender, race and class in British parliament. Cambridge: Cambridge University Press, 1995.

Panebianco, A. Modeli di partito: organizzazione e potere nei partiti politici. Roma: Il Mulino, 1982.

Pennings, P.; HAZAN, R. "Democratizing candidate selection: causes and consequences". Party Politics, vol. 7, no 3, p. 267-275, 2001.

PeRES, P. "Revisitando a 'teoria geral dos partidos', de Maurice Duverger". Revista Brasileira de Informação Bibliográfica em Ciências Sociais - BIB, vol. 68, no 2, p. 17-58, 2009.

PerissinotTo, R.; Bolognesi, B. "O recrutamento político no PT e no PFL paranaense nas eleições de 2006: sugestões de pesquisa". Revista Mediações, vol. 14, no 1, p. 143-169, 2009.

Perissinotto, R.; Miríade, A. "Caminhos para o parlamento: candidatos e eleitos nas eleições para deputado federal em 2006". Dados, vol. 52, no 2, p. 301-303, 2009.

PolyA, G. How to solve it. Princeton: Princeton University Press, 1973.

POPPER, K. The logic of scientific discovery. London: Hutchinson and Co, 1959.

POWER, T.; MOCHEL, M. Political recruitment in an executive-centric system: presidents, governors, and ministers in Brazil. In: Siavelis, P.; Morgenstein, S. (eds). Pathways to power: political recruitment and candidate selection in Latin America. Pennsylvania: Pennsylvania State University Press, 2008.

PREWITT, K. The recruitment of political leaders. Indianapolis: Bobbs-Merrill, 1970. 
RAHAT, G.; HAZAN, R. "Candidate selection methods: an analytical framework". Party Politics, vol. 7, no 3, p. 297-322, 2001.

RANneY, A. Pathways to parliament: candidate selection in Britain. Madison: The University of Wisconsin Press, 1965.

. Candidate selection. In: Butler, D; Penniman, H.; Ranney, A. (eds.). Democracy at the polls: a comparative study of competitive national elections. Washington: American Enterprise Institute for Public Research, 1981.

Rodrigues, L. M. Partidos, ideologia e composição social: um estudo das bancadas partidárias da Câmara dos Deputados. São Paulo: Edusp, 2002.

Políticos do Brasil: uma investigação sobre o patrimônio declarado e a ascensão daqueles que exercem o poder. São Paulo: Publifolha, 2006.

ROHDE, D. "Risk bearing and progressive ambition: the case of members of the United States House of Representatives". American Journal of Political Science, vol. 23, p. 1-26, 1979.

Salter, J. T. (ed.). The American politician. Chapel Hill: University of North Carolina Press, 1938.

SAMUELS, D. Ambition, federalism, and legislative politics in Brazil. Cambridge: Cambridge University Press, 2003.

. Political ambition, candidate recruitment, and legislative politics in Brazil. In: SIAVELIS, P.; Morgenstern, S. (eds.). Pathways to power: political recruitment and candidate selection in Latin America. Pennsylvania: Pennsylvania State University Press, 2008.

SCARrow, S. Parties and their members. Oxford: Oxford University Press, 1996.

Parties without members? Party organization in a changing electoral environment. In: DALton, R.; WAttenberg, M. (eds.). Parties without partisans: political changing in advanced industrial democracies. Oxford: Oxford University Press, 2000.

Beyound party members: changing approaches to partisan mobilization. Oxford: Oxford University Press, 2015.

SCARrow, S.; GeZgor, B. "Declining membership, changing members? European political party members in a new era". Party Politics, vol. 16, nº 6, p. 823-843, 2010.

SCARROW, S.; WEBB, P. "Assessing party organizational change: participation, representation and power", APSA Proceedings, American Political Science Association Annual Meeting, Chicago, 2013.

Schattschneider, E. Party government. New York: Holt, Rinehart and Wiston, 1942.

SCHelesinger, J. The crisis of the old order. New York: Mariner Books, 1957. Co, 1966 .

Ambition and politics: political careers in the United States. Chicago: Rand McNally and Political parties and the winning of office. Ann Arbor: University of Michigan Press, 1991.

Seligman, L. Recruiting political elites. New York: General Learning Press, 1971.

SEYD, P. "New parties, new politics? A case study of the British Labour Party". Party Politics, vol. 5, no 3, p. 383-405, 1999.

SiAVELIS, P. "The hidden logic of candidate selection for Chilean parliamentary elections". 
Comparative Politics, vol. 34, no 4, p. 419-438, 2002.

Siavelis, P.; Morgenstern, S. Political recruitmen and candidate selection in Latin America: A framework for analysis. In: SiAvelis, P.; MORGENSTERn, S. (eds.). Pathways to power: political recruitment and candidate selection in Latin America. Pennsylvania: Pennsylvania State University Press, 2008.

SNeATH, P.; SOKAL, R. Numerical taxonomy: the principles and practice of numerical classification. San Francisco: Freeman, 1973.

SPECK, B. "Political ambition and the spoils of victory: an exploratory analysis of party membership in Brazil", ECPR Joint Sessions, Workshop: Contemporary Meaning of Party Membership, Salamanca, 2014.

STAR, S. Categories and cognition: material and conceptual aspects of large-scale category systems. In: DERRY, S.; GeRnSBACHER, M. (eds.). Interdiscipinary collaboration: an emerging cognitive science. New Jersey: LEA Inc, 2005.

TiRyakian, E. Typologies. In: Sills, D. (ed.). International Encyclopedia of the Social Sciences. New York: MacMillan and Free Press, 1968.

VAn Biezen, I. Political parties in new democracies: party organization in Southern and East-Central Europe. London: Palgrave MacMillan, 2003.

Van Biezen, I.; Poguntke, T. "The decline of membership-based politics". Party Politics, vol. 20, no 2, p. 205-216, 2014.

VAn Biezen, I.; MAIR, P.; PoguntKe, T. "Going, going, gone? The decline of party membership in contemporary Europe". European Journal of Political Research, vol. 51, p. 24-56, 2012.

VAN BIEZEN, I.; KoPECKY, P. "The State and the parties: public funding, public regulation and rent seeking in contemporary democracies". Party Politics, vol. 13, p. 235-254, 2007.

VAN HAUTE, E. Party membership: an understudied mode of political participation. In: VAN HAUTE, E. (ed.). Party membership in Europe: explorations into the anthills of party politics. Bruxelles: Université de Bruxelles, 2011.

WARE, A. Political parties and party systems. Oxford: Oxford University Press, 1996.

WeBB, P. Party organizational change in Britain: the iron law of centralization?. In: KATZ, R.; MAIR, P. (eds.). How parties organize. London: Sage, 1995.

WebB, P.; Farrel, D.; Holliday, I. Political parties in advanced industrial democracies. Oxford: Oxford University Press, 2002.

Weber, M. Ciência e política: duas vocações. São Paulo: Cultrix, 1992 [1919].

WhITELEY, P. "Is the party over? The decline of party activism and membership across the democratic world". Party Politics, vol. 17, no 1, p. 21-44, 2011.

Whiteley, P.; SeYd, P. "The dynamics of party activism in Britain: a spiral of demobilization?". British Journal of Political Science, vol. 28, pp. 113-138, 1998. 
UMA TIPOLOGIA DO RECRUTAMENTO PARTIDÁRIO

\section{Resumo}

Uma tipologia do recrutamento partidário

O recrutamento de lideranças políticas é uma das funções mais relevantes desempenhadas pelos partidos nas democracias contemporâneas. Porém, a literatura especializada costuma analisar apenas alguns aspectos relacionados à etapa final desse processo, como a seleção de candidatos, o perfil socioeconômico de lideranças já eleitas e as carreiras dos políticos, negligenciando as estratégias e modalidades de atração e formação de novos quadros empregadas pelas organizações partidárias. Consequentemente, até o momento, não foram desenvolvidos modelos heurísticos que permitam observar e analisar o recrutamento em seus diversos momentos. Nosso objetivo neste artigo é propor uma tipologia para o estudo do recrutamento partidário em todas as suas etapas. Para tanto, apresentamos uma definição conceitual que considera o recrutamento partidário como um processo abrangente que envolve três aspectos: (1) a atração de filiados para a organização; (2) a formação/treinamento dos futuros quadros; e (3) sua posterior alocação em postos na burocracia do partido ou nos governos e/ou sua seleção como candidato a cargos representativos, com o eventual exercício de algum mandato. Baseados nessa definição, propomos um modelo de análise que enquadra o recrutamento partidário de acordo com seus tipos, subtipos, formas, meios, modalidades e submodalidades.

Palavras-chave: recrutamento partidário; recrutamento político; tipologia do recrutamento partidário; filiação partidária; elites partidárias

\section{Abstract \\ A typology of party recruitment}

The recruitment of political leadership is one of the most relevant functions carried out by parties in contemporary democracies. Yet, the specialized literature often addresses only a few aspects related to the last stage of the process, which covers candidate selection, the socio-economic profile of elected leaders, and the careers of the relevant politicians, neglecting the strategies and modalities of attraction and the training of new cadres by party organizations. Thus, up to the present, no heuristic model has actually been developed in order to enable the observation and analysis of recruitment in its several moments. Our aim in this text is to present a typology for the study of party recruitment in all its stages. Therefore, we provide a conceptual definition which regards party recruitment as a comprehensive process that involves three aspects: (1) attracting new members to the organization; (2) training future cadres; and (3) allocating them, later, to the party's bureaucratcy or to government positions and/or selecting them as candidates for representative positions with the possibility of carrying out a mandate. Based on this definition, we propose a model of analysis that frames party recruitment according to its types, subtypes, ways, means, modalities, and sub-modalities.

Keywords: party recruitment; political recruitment; typology of party recruitment; party affiliation; party elites

\section{Resumen}

\section{Una tipología de reclutamiento partidario}

El reclutamiento de líderes políticos es una de las funciones más relevantes llevadas a cabo por los partidos en las democracias contemporáneas. No obstante, la literatura especializada analiza solamente algunos aspectos relacionados con la última etapa del proceso, o sea la selección de candidaturas, el perfil socio-económico de los líderes electos y las carreras de los políticos. Así, los investigadores descuidan otros aspectos relevantes tales como las estrategias y modalidades de atracción y formación de nuevos cuadros partidarios. Por consecuencia, hasta la actualidad no se desarrolló cualquier modelo heurístico que permita la observación y el análisis del reclutamiento en sus diferentes momentos. Nuestro objetivo en este texto es presentar una tipología para el estudio de reclutamiento partidario en todas sus etapas. Por lo tanto, ofrecemos la definición conceptual que 
PAULO PERES; AMANDA MACHADO

considera el reclutamiento partidario como un proceso amplio que incluye tres momentos: (1) la atracción de nuevos miembros para la organización, (2) la formación política de los futuros cuadros partidarios y (3) su posterior asignación a la burocracia o a cargos en gobiernos, así como su selección para concurrir a los puestos de representación. Sobre la base de esta definición, se propone un modelo tipológico que analiza el reclutamiento partidario de acuerdo con sus tipos, subtipos, formas, medios, modalidades y sub-modalidades.

Palabras-Clave: reclutamiento partidario; reclutamiento político; tipología de reclutamiento partidario; afiliación partidaria; élites partidarias

\section{Résumé}

Une typologie du recrutement des partis

Le recrutement de cadres politiques est l'une des fonctions les plus importantes des partis dans les démocraties contemporaines. Cependant, la littérature spécialisée n'analyse souvent que quelques détails concernant la dernière étape de ce processus, comme la sélection des candidats, le profil socio-économique des cadres déjà élus et leur carrière politique, et elle accorde moins d'importance aux stratégies et aux modalités des organisations des partis pour attirer et former de nouveaux cadres. De cette façon, jusqu'à présent, aucun modèle heuristique n'a été développé pour nous permettre d'observer et d'analyser le recrutement dans ses différentes étapes. Notre objectif avec ce texte est de proposer une typologie pour l'étude du recrutement des partis dans toutes ses étapes. Pour cela, nous présentons une définition conceptuelle qui considère le recrutement des partis comme un processus global qui possède trois aspects: (1) attirer des membres pour l'organisation, (2) la formation des futurs cadres et (3) leur placement postérieur à des postes de la bureaucratie du parti ou dans des gouvernements et/ou la possibilité de les choisir comme candidats pour des fonctions représentatives, avec un éventuel mandat politique à la clé. En tenant compte de cette définition, nous proposons un modèle d'analyse qui encadre le recrutement des partis selon ses types, ses sous-types, ses formes, ses moyens, ses modalités et ses sous-modalités.

Mots-clés: recrutement des partis; recrutement politique; typologie du recrutement des partis; affiliation politique; élites des partis

Artigo submetido à publicação em 7 de janeiro de 2015. Versão final aprovada em 23 de fevereiro de 2017. 